DOE PC. $90174=T 4$

Technical Progress Report

Fourth Quarter

(July 1, 1991 - September 30, 1991)

Development of the Selective Coagulation Process

Principal Investigators

R.-H. Yoon and G.H. Luttrell

Virginia Center for Coal and Minerals Processing

Virginia Polytechnic Institute and State University

Blacksburg, Virginia 24061-0258

Contract Number:

DE-AC22-90PC90174

\section{Project Manager}

Richard B. Read

United States Department of Energy

Pittsburgh Energy Technology Center

P.O. Box 10940

Pittsburgh, Pennsylvania 15236-0940

\title{
MASTER
}

DISTRIBUTION OF THIS DOCUMENT IS UHLIMTED

DH DOCUMENT IS UNLIMITED 


\begin{abstract}
Recent studies carried out at the Virginia Center for Coal and Minerals Processing (VCCMP) have resulted in the development of a novei agglomeration process for upgrading ultrafine coal. This process, known as selective hydrophobic coagulation (SHC), is based on the new finding that hydrophobic materials such as coal can be selectively coagulated and recovered from dispersed suspensions of coal and hydrophilic mineral matter. The driving force for this coagulation of coal is believed to be a hydrophobic force which has not been previously recognized in the classical DLVO theory. In most cases, simple $\mathrm{pH}$ control is all that is required in order to (i) induce the coagulation of the coal particles and (ii) effectively disperse the particles of mineral matter.
\end{abstract}

During the past quarter, it was established in Task 2.1 that the Surface Forces Apparatus was operating satisfactorily. Work on generating force-distance curves for the mica/DDOA bromide model hydrophobic system was initiated and the preliminary results were found to be encouraging. In Task 2.3, a population balance model for hydrophobic coagulation was completed. Predictions of the coagula size distributions formed by the SHC process were found to be in good agreement with experimentally determined size distributions. In Task 2.4 , work initiated in the previous quarter on the measurement of coagula size for Elkhorn No. 3 seam coal was expanded to cover the effects of $\mathrm{pH}$, agitation intensity, initial particle size and feeds solid concentration on mean coagula size. The effects of $\mathrm{pH}$ and agitation speed on the coagulation behavior of the Pittsburgh No. 8 seam coal were also examined during the past quarter. The results obtained from these tests indicated that for each coal an optimum $\mathrm{pH}$ existed which maximized the separation efficiency. Under typical operating conditions, finer initial particle size distributions were found to enhance the growth of coagula, while lower solids concentrations and higher agitation intensities were detrimental to coagula growth.

In Task 3.4, studies were undertaken to determine the effect of using small amounts of hydrocarbon oils to enhance coagula growth/separation. The results of these tests suggest that the addition of hydrocarbon oils has little or no beneficial impact on coagula growth under the operating 
conditions examined. In Task 3.6, bench-scale tests were carried out on the Elkhorn No. 3 seam coal using a continuous sedimentation separator. The effects of several key operating parameters on process performance were examined in this series of tests. These included volumetric feed flow rate, $\mathrm{pH}$, solids concentration, initial particle size, and the addition of archelating agent and dispersant. The experimental trends were similar to those obtained from the multi-stage batch tests conducted during the earlier phases of this investigation. However, the ash and sulfur contents of the clean coal products were significantly higher in the continuous tests due to the relatively large amount of entrained and/or entrapped mineral matter after only a single stage of processing. This indicates that multiple stages of recleaning are required to obtain high separation efficiencies in the $S H C$ process. Preliminary test work was also conducted on a high-sulfur coal from the Pittsburgh No. 8 seam. These tests suggested that the SHC process does not work as well with the Pittsburgh No. 8 coal. The poor separation efficiencies were attributed to the natural hydrophobicity of coal pyrite, the presence of iron (which negatively affects selectivity), and/or the lower natural hydrophobicity of this particular coal sample. In Task 3.7, a 27 test Box-Behnken experimental design was carried out to establish the optimum operating conditions for the SHC process. The parameters studied included feed rate, feed solids concentration, mudline depth and feed inlet point. Analysis of the test data is currently underway.

\section{PROJECT OBJECTIVES}

The aim of this project is to develop an economical method for producing low-sulfur and lowash coals using the selective hydrophobic coagulation (SHC) process. This work has been divided into three tasks: 1) project planning and sample acquisicion; 2) studies of the fundamental mechanism(s) of the selective coagulation process and the parameters that affect the process of separating coal from both the ash-forming minerals and pyritic sulfur; and 3) bench-scale process 
development test work to establish the best possible method(s) of separating the hydrophobic coal coagula from the dispersed mineral matter.

\section{PROJECT TASKS}

Task 2. Fundamentals

Task 2.1 Surface Forces Measurements

The effect of dodecylamine additions on the force-distance curves obtained between two mica plates in water were presented in the last technical progress report. Although the tests were preliminary in nature, the experimental results were in good agreement with those previously reported in the literature and confirmed that the Surface Force Apparatus was working correctly.

Experimental measurements are now under way to determine the total interaction forces for a model hydrophobic system obtained by coating mica surfaces with dimethyldioctadecylammonium (DDOA) bromide. This model system is being utilized in this study since the surface roughness of coal prevents it from being used directly in the Surface Force Apparatus. Monolayer coatings exhibiting contact angles in excess of $100^{\circ}$ (as measured by the Wilhemy slide method) have been prepared on the mica surfaces using a Joyce Loebl Langmuir Mini-Trough. Force-distance curves for this system will be presented in the next technical progress report.

\section{Task 2.3 Modeling of Hydrophobic Coagulation}

A dynamic population balance model has been developed from aggregate growth and breakage models described in Task 2.3 of the previous quarterly reports. The general conservation equation used in the development of the model can be expressed as:

$$
\text { Accumulation }=\text { Input }- \text { Output }+ \text { Net Generation. }
$$

Aggregate size is the only property considered in the present population balance model. By applying the general theorem of Equation [1] to a closed coagulation system, the basic deterministic equation 
for the number balance of any $z$ th aggregate size class is obtained as follows:

$$
\begin{aligned}
\frac{\delta n(z, t)}{\delta t}= & \frac{1}{2} \sum_{i=1}^{t=z-1} R C(z-i, i) n(z-i, t) n(i, t)-n(z, t) \sum_{i=1}^{\infty} R C(z, i) n(i, t) \\
& +\sum_{i=z+1}^{\infty} S(i) B(z, i) n(i, t)-S(z) n(z, t), \quad z=3,4, \ldots,
\end{aligned}
$$

where $n(z, t)$ represents the time dependence for the number concentration of the $z$ th size class, $R C(z, i)$ is the coagulation rate between aggregates in the $z$ th size class and the $i$ th size class, $S(z)$ is the breakage rate of aggregates in the $z$ th size class, and $B(z, i)$ is the breakage function representing the fraction of $i$ th-class aggregates formed by the breakage of a $z$ th-class aggregate.

The first term in Equation [2] represents the increase in the number concentration of $z$ th size class aggregates which are formed by binary aggregation of smaller aggregates and/or particles within a specific unit of time. The second term describes the decrease in the number concentration of $z$ thclass aggregates due to coagulation between a zth-class aggregate and any other aggregate. Together, these two terms describe the aggregate growth behavior. The third term accounts for the appearance of $z$ th-class aggregates by the breakage of a larger aggregate, and the fourth represents the disappearance of $z$ th-class aggregates due to their breakage into a spectrum of smaller daughter aggregates. Together, the third and fourth terms describe aggregate breakage behavior.

It has been found experimentally that a maximum stable aggregate size exists for each coagulation system. Therefore, the infinity sign in Equation [2] can be replaced with a maximum aggregate size, $N$. Under this constraint, the application of the general population balance equation to (i) the primary particle, (ii) the dimer aggregate, and (iii) the top aggregate class yields the following equations:

$$
\frac{\delta n(1, t)}{\delta t}=-n(1, t) \sum_{i=1}^{N} R C(1, i) n(i, t)+\sum_{i=2}^{N} X(i) B(1, i) n(i, t)
$$




$$
\frac{8 n(2, t)}{8 t}=R C(1,1) n(1, t)^{2}-n(2, t) \sum_{i=1}^{N} R C(2, i) n(i, t)+\sum_{i=3}^{N} S(i) B(2, i) n(i, t)-S(2) n(2, t)
$$

$$
\frac{\delta n(N, t)}{\delta t}=\frac{1}{2} \sum_{i=1}^{N-1} R C(i, N-i) n(i, t) n(N-i, t)-n(N, t) \sum_{i=1}^{N} R C(i, N) n(i, t)-S(N) n(N, t)
$$

In order to complete the description of the closed system, an additional constraint must be imposed on Equations [3]-[5], viz.:

$$
\frac{8 \sum_{z=1}^{N} z n(z, t)}{8 t}=0
$$

Equation [6] indicates that the total mass of the solids in a system does not change with time. In integral form, this constraint can be written as:

$$
\sum_{z=1}^{N} z n(z, t)=n(1,0)
$$

The result of the above analysis is a macroscopic population balance model that describes both the aggregate growth and aggregate breakage events. It is interesting to note that if the breakage event is neglected in Equation [2], the model simplifies to the discrete form of the well-known Smoluchowski's coagulation equation. Therefore, the present model can be applied to more general coagulation systems than can the model developed by Smoluchowski, which only accounts for special cases.

In this study, the population balance model equation was developed for 500 individual size fractions $(N=500)$. After predetermination and/or calculation of all parameters and constants, the equations were solved numerically using the backward differentiation formula known as Gear's stiff 
method, and a Jacobian matrix. The solution procedure is summarized in the schematic flow chart shown in Figure 1.

In order to validate the model developed in the present work, the predicted aggregate size distribution was compared with that of an aggregate generated from a -400 mesh Elkhorn No. 3 coal sample. Aggregate sizes were estimated from settling rate tests carried out using the Andreasen pipette technique. The simulations were conducted using model parameters determined for the Lower Cedar Grove coal sample at the critical coagulation $\mathrm{pH}$. These parameters were believed to be reasonably applicable to the Elkhorn searn coal because of the similarities between the two coal samples. In the model simulation, an experimentally determined $D_{\infty}$ value of $16 \mu \mathrm{m}$ was used as the primary particle size, and a binary breakage function was used in place of the proposed Broadbent and Callcott function to obtain better agreement between the experimental and simulation results.

The experimental and predicted aggregate size distributions obtained in this series of tests are shown in Figure 2. The experimentally measured aggregate top size of approximately $50 \mu \mathrm{m}$ is almost identical to that predicted by the model. The lack of agreement in the aggregate size range greater than $50 \mu \mathrm{m}$ may be attributed to inaccuracies in the aggregate size measurements obtained using the Andreasen pipette. It is also possible that the model is unable to predict the size distribution? of particles in the tail of the fine size range due to the nature of the binary breakage function used in the simulation.

\section{Task 2.4 Measurement of Coagula Size}

As reported last quarter, a Lasentec Model 100 particle size analyzer is now being used to measure coagula size as a function of various test conditions. Utilizing back-scattered light to infe: particle size, the Lasentec analyzer allows coagula size measurements to be conducted in-situ. The instrument was calibrated with samples of pre-cleaned Elkhorn No. 3 and Pittsburgh No. 8 seam coals which had been wet-screened into several size fractions between 28 and 500 mesh. First the size fractions were analyzed by an Elzone $80-\mathrm{XY}$ particle size analyzer to obtain the actual volume mean 


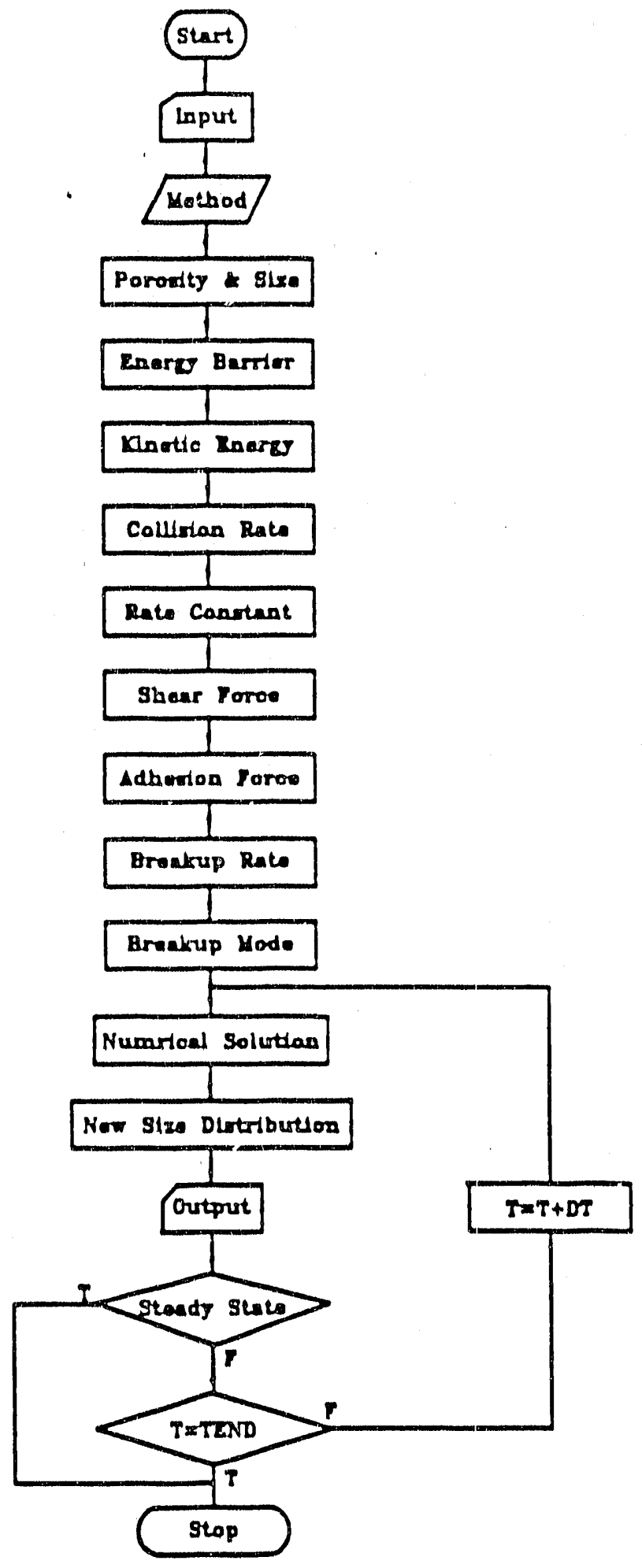

Figure 1: Schematıc diagram of the computer program for simulating coagulation kinetic behavior. 


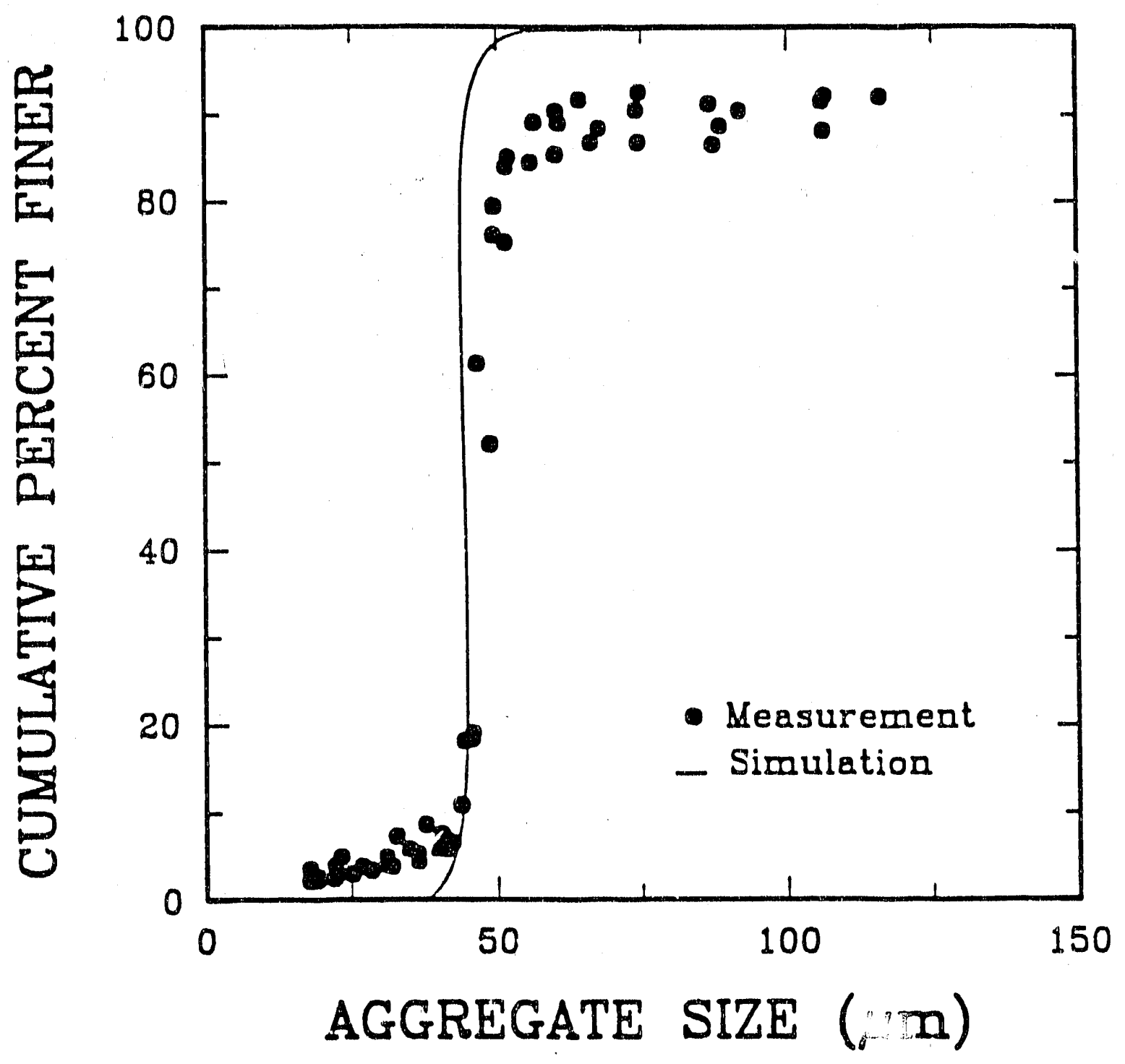

Figure 2: A comparison of aggregate size distributions obtained from computer simulation and experimenta? measuiements at $\mathrm{pH} 8.4$. 
particle diameter $\left(D_{s 0}\right)$. Then the actual $D_{s 0}$ of each size class was compared to the corresponding $D_{s 0}$ determined using the Lasentec analyzer. As shown in Figures 3 and 4, this procedure allowed calibration curves to be constructed for each coal sample. The actual $D_{s o}$ for the Elkhorn No. 3 and Pittsburgh No. 8 coals could be determined from the following linear relationships:

$$
\text { ElkhornNo.3: Actual } D_{50}=1.13\left(\text { Lasentec } D_{50}\right)-106.91 \text {, }
$$

PittsburghNo.8: Actual $D_{50}=1.32\left(\right.$ Lasentec $\left.D_{50}\right)-187.77$,

During this reporting period, coagula size distributions for the Elkhorn No. 3 coal were measured using the Lasentec size analyzer for three different initial particle sizes and four different solids concentrations. In many of the tests, the effects of $\mathrm{pH}$ and impeller speed were also examined. The samples used for this study were prepared by wet-grinding in a laboratory stirred-ball mill for a predetermined amount of time to achieve the desired particle size. Following grinding, each sample was transferred to a 4-inch diameter mixing vessel having eight $1 / 4$-inch baffles, the solids concentration was adjusted to $2 \%$ solids by weight, and the $\mathrm{pH}$ was adjusted to the desired value using sodium hydroxide. Also, unless otherwise stated, potassium chloride was added as a supporting electrolyte at a concentration of $10^{-3} \mathrm{M}$. The slurry was then agitated at $500 \mathrm{rpm}$ using a $1 \frac{1 / 2-\text { inch }}{}$ diameter turbine impeller. After conditioning, the coagula size distributions were measured in-situ using the Lasentec particle size analyzer. These measurements were then corrected, using Equation [8], to obtain the actual $D_{50}$ of the coagula.

The effect of the initial mean particle size (IPS) on the resultant mean coagula size $\left(D_{50}\right)$ was studied as a function of agitation speed and $\mathrm{pH}$. Three different initial particle sizes were prepared by wet grinding samples of Elkhorn No. 3 coal for 2, 5, and 10 minutes in a laboratory attrition mill. Mean particle sizes for these samples were determined with an Elzone 80-XY particle size analyzer to 


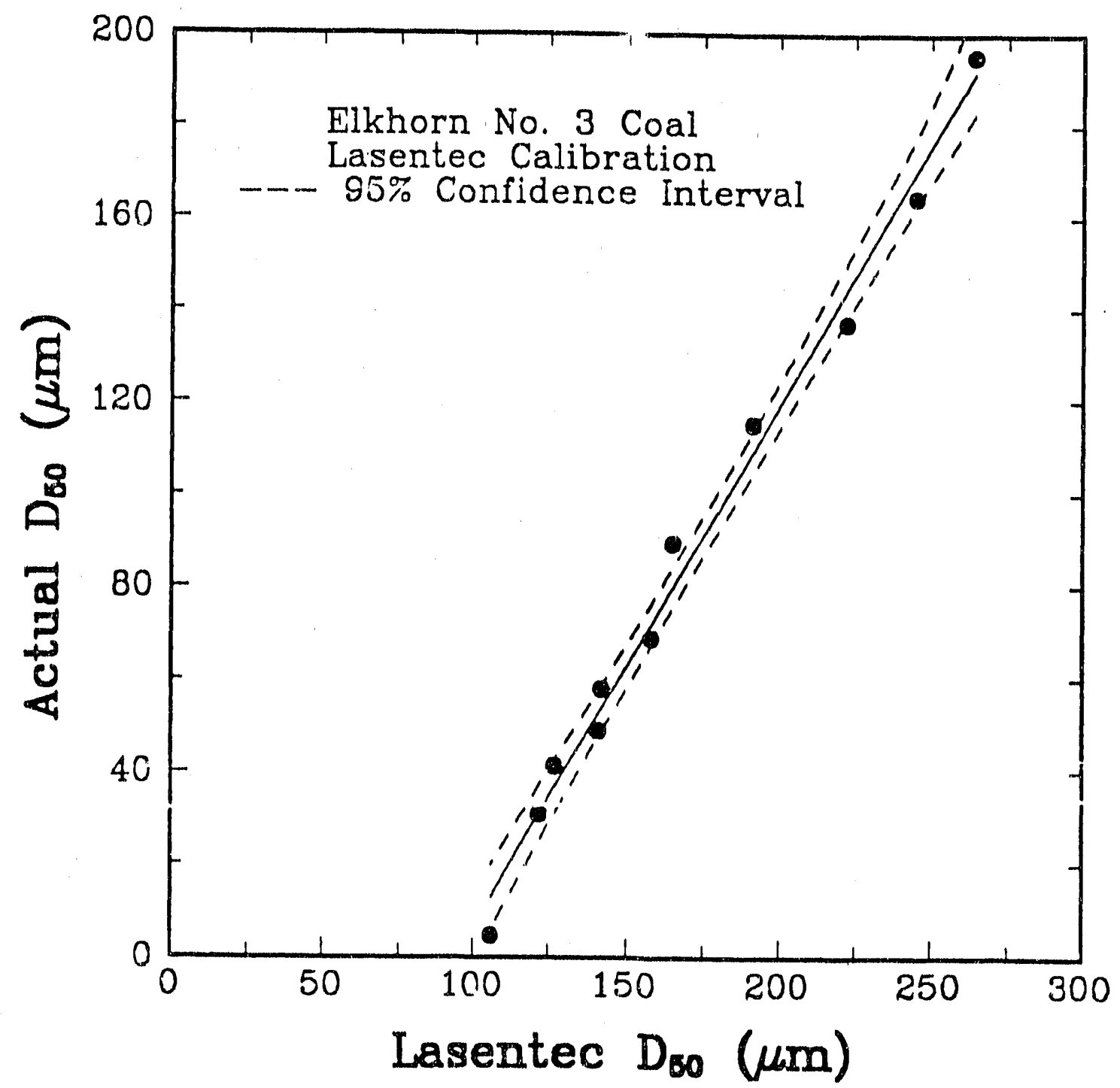

Figure 3: $\quad$ Actual $D_{50}$ vs. Lasentec $D_{s,}$ for Elkhorn No. 3 seam coal. 


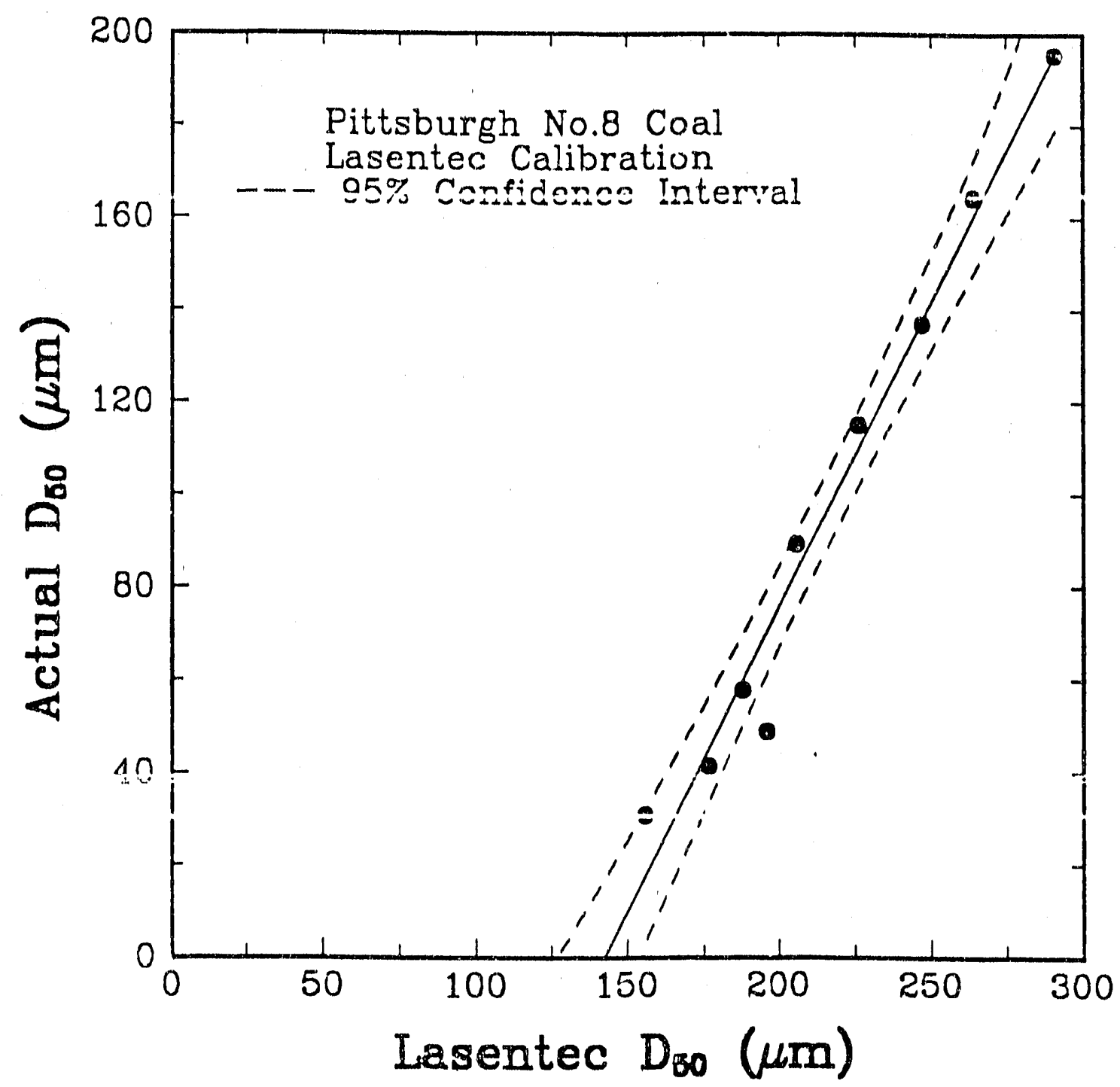

Figure 4: $\quad$ Actual $D_{s o}$ vs. Lasentec $D_{s o}$ for Pittsburgh No. 8 seam coal. 
be $7.2,5.3$ and $3.6 \mu \mathrm{m}$, respectively.

Table I provides a summary of the coagula size measurements conducted as functions of initial particle size, agitation speed and pH. Only two initial particle sizes, 3.6 and $7.2 \mu \mathrm{m}$, were examined in detail in this first series of tests. For most experimental conditions, the test data indicate that the mean coagula size increases with a decrease in the initial particle size, i.e., finer feeds produce larger coagula. This finding is reasonable since (i) the particle population, and hence collision frequency, increases as the initial particle size decreases and (ii) particle detachment is reduced by a decrease in particle size due to the reduced magnitude of the inertial forces on finer particles. As shown in Table I, the increase in coagula size with a decreasing initial particle size is most pronounced at $\mathrm{pH}$ values 8.0 and 8.5 . However, when the coagulation experiments were conducted at $\mathrm{pH} 7.5$, the reverse trend was observed for agitation speeds greater than $25 \mathrm{rpm}$. This behavior is illustrated more clearly in Figure 5, which shows coagula size distributions measured at $37 \mathrm{rpm}$ and $\mathrm{pH}$ 7.5. As shown, the coagula size distributions shift toward finer sizes as the initial particle size decreases. An explanation for the reversal in behavior under these conditions is not presently available.

Table I: $\quad$ Results illustrating the effect of initial particle size on the mean coagula size over a range of $\mathrm{pH}$ values and agitation speeds.

\begin{tabular}{|c|c|c|c|c|c|c|}
\hline \multirow{3}{*}{$\mathbf{R}^{\mathbf{m}} \mathbf{M}$} & \multicolumn{6}{|c|}{ Mean Coagula Size $(\mu \mathrm{m})$} \\
\hline & \multicolumn{2}{|c|}{ At pH 7.5} & \multicolumn{2}{|c|}{ At pH 8.0} & \multicolumn{2}{|c|}{ At pH 8.5} \\
\hline & $\mathrm{IPS}=3.6$ & $\mathrm{IPS}=7.2$ & $\operatorname{IPS}=3.6$ & $\mathrm{IPS}=7.2$ & $\mathrm{IPS}=3.6$ & $\mathrm{IPS}=7.2$ \\
\hline 25 & 355 & 288 & 189 & 175 & 92.1 & 50.2 \\
\hline 50 & 167 & 199 & 132 & 116 & 74.0 & 38.9 \\
\hline 75 & 90.7 & 156 & 72.8 & 48.0 & $: 3$ & 31.0 \\
\hline 100 & 67.2 & 71.7 & 52.5 & 32.1 & 59.3 & 17.4 \\
\hline
\end{tabular}

IPS $=$ Initial Particle Size (in $\mu \mathrm{m}$ ) 


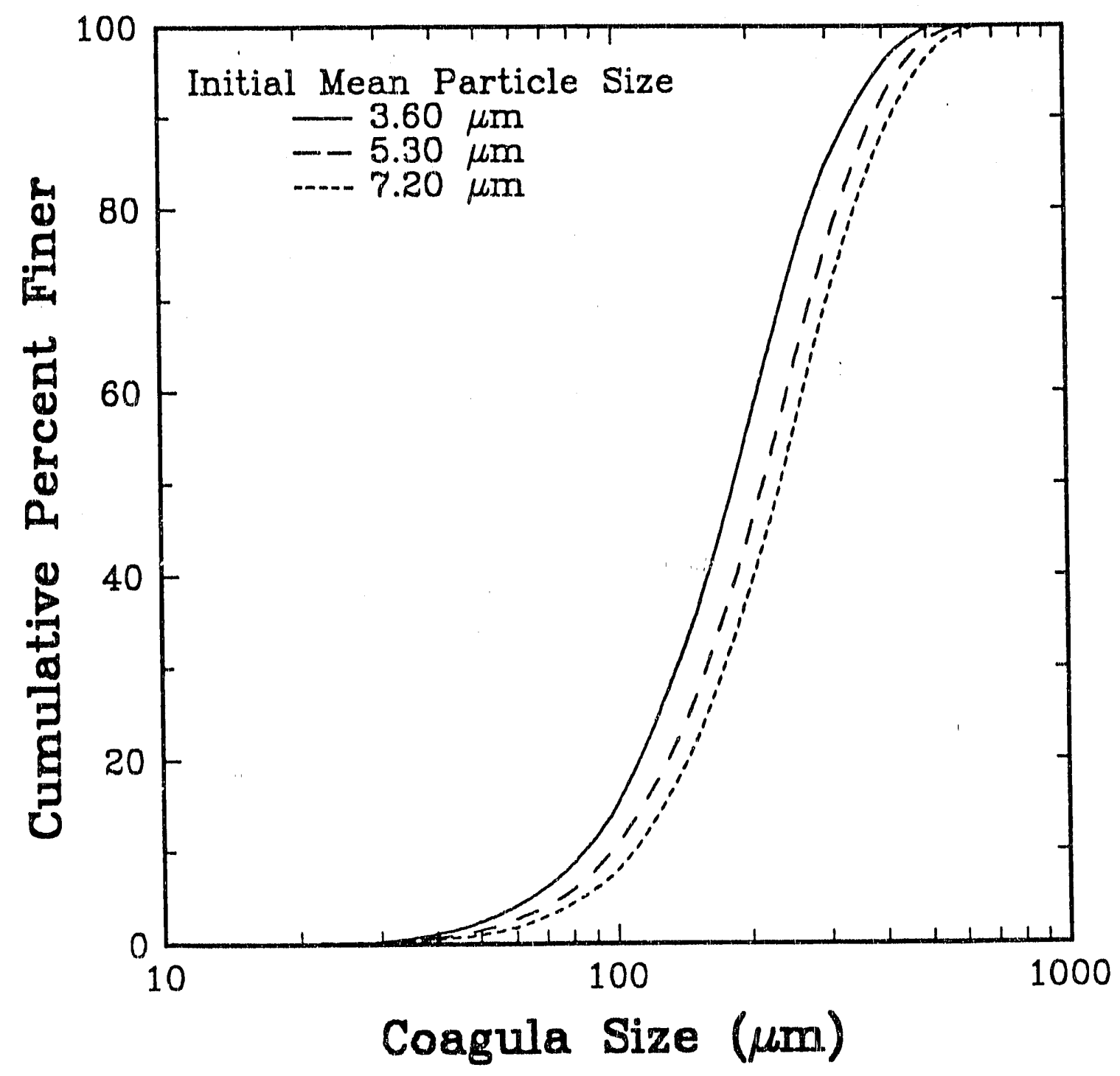

Figure 5: The effect of initial particle size on the size of coagula produced at an agitation speed of $37 \mathrm{rpm}$ and $\mathrm{apH}$ of 7.5 . 
Additional coagula size measurements were conducted at solids concentrations of $0.1 \%$, $0.5 \%, 1.0 \%$, and $2.0 \%$ by weight in order to develop a better understanding of the effects of particle population on coagulation behavior. These tests were conducted using a pre-cleaned Elkhorn No. 3 coal sample that had been ground for 5 minutes in a laboratory attrition mill. Both the pH and agitation speed were held constant, at 7.5 and $25 \mathrm{rpm}$, respectively, during this series of tests. As shown in Figure 6, there was a slight decrease in the coagula $D_{s o}$ size from $325 \mu \mathrm{m}$ to $261 \mu \mathrm{m}$ when the solids content was decreased from $2.0 \%$ to $1.0 \%$. Further decreases in solids content to $0.5 \%$ and $0.1 \%$ resulted in sharp drops in the coagula $D_{50}$ sizes to $104 \mu \mathrm{m}$ and $37 \mu \mathrm{m}$, respectively. These results may be explained by the fact that the number of particles per unit volume decreases as the solids content is decreased. As a result, the particle collision frequency decreases with decreasing particle population, resulting in a decrease in coagula size.

Coagula size distributions for the Pittsburgh No. 8 coal seam sample were also determined during this reporting period. In general, the coagula obtained with this coal are smaller than those obtained with the Elkhorn No. 3 coal sample. This difference may be caused by the lower characteristic hydrophobicity of the ?ittsburgh No. 8 coal, as reported in Task 2.2 of the second quarterly report. Typical coagula and initial size distributions, measured in-situ before and after the addition of Lomar-D dispersant to a coagulated suspension, are compared in Figure 7. In this case, the $D_{50}$ size of the dispersed particles was found to be $4.6 \mu \mathrm{m}$ at a $\mathrm{pH}$ value of 9 . The $D_{50}$ of the coagula was found to be $143 \mu \mathrm{m}$ at an agitation speed of $25 \mathrm{rpm}$ and $\mathrm{pH}$ of 6.5 .

In order to determine the effects of $\mathrm{pH}$ on the coagulation behavior of the Pittsburgh No. 8 seam coal, coagula size distributions were determined at $\mathrm{pH}$ values between 4 and 8 . As shown in Figure 8, the coagula size increased as the $\mathrm{pH}$ was raised from 4 to 6 , and then decreased as $\mathrm{pH}$ was further increased to $\mathrm{pH}$ 7. The decrease in the coagula size beyond $\mathrm{pH} 6$ correlates well with the critical coagulation $\mathrm{pH}\left(\mathrm{pH}_{C}\right)$ of 6.2 reported in the first quarterly report.

The effect of agitation speed on the coagulation behavior of the Pittsburgh No. 3 coal was 


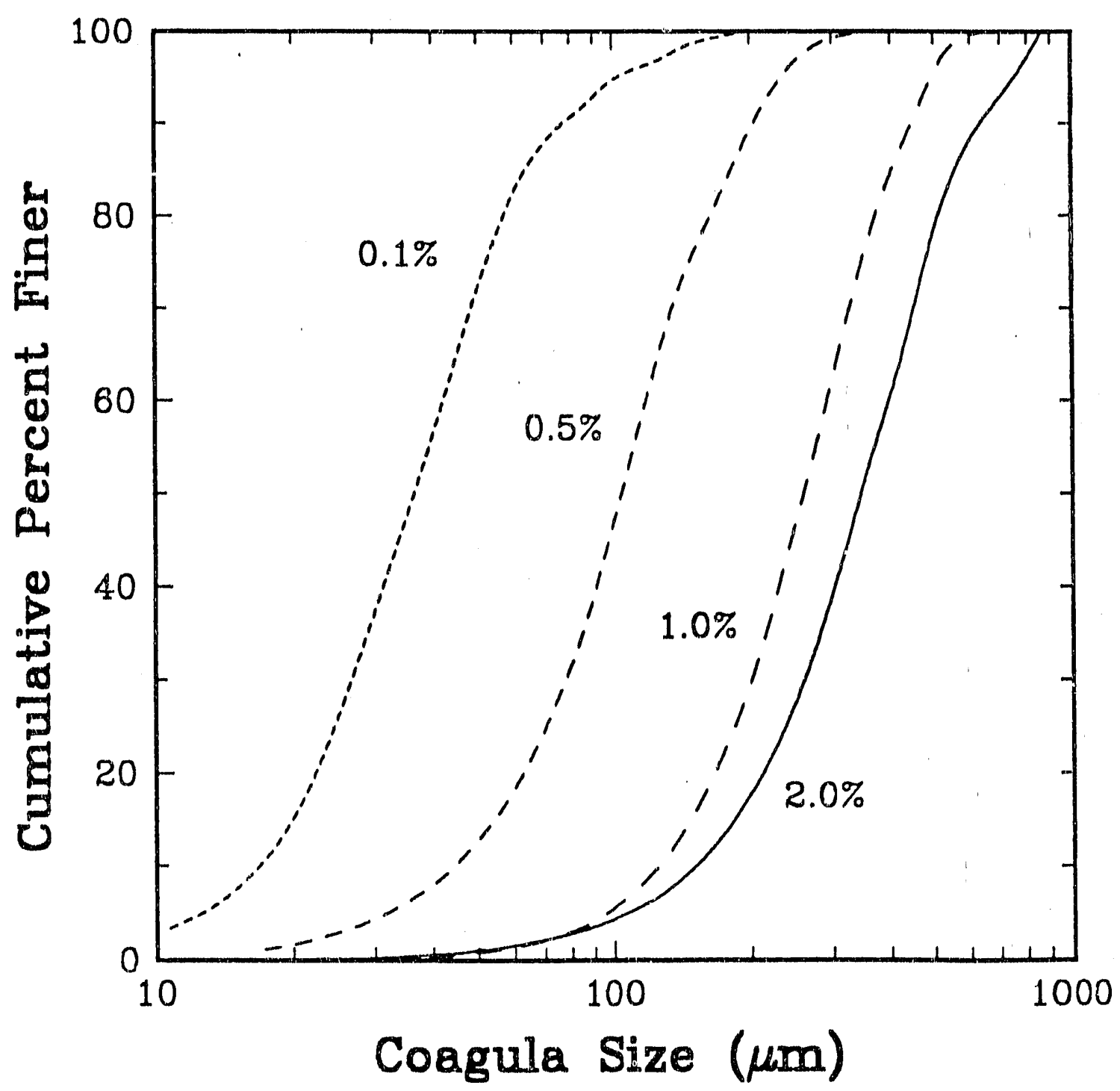

Figure 6: The effect of solids concentration on the size of coagula produced at an agitation speed of $25 \mathrm{rpm}$ and a pH of 7.5. 


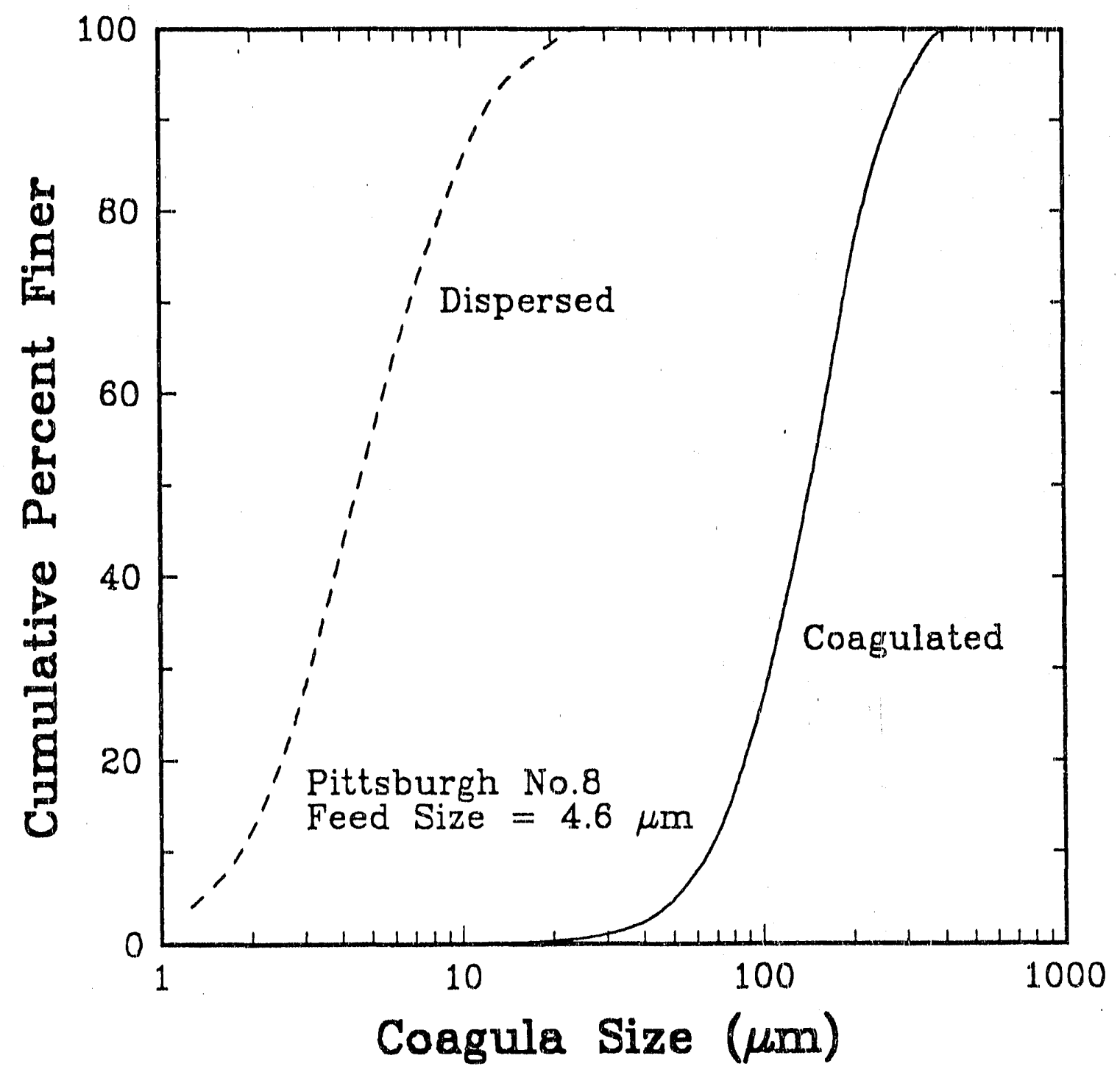

Figure 7: Comparison of the dispersed particle and coagulated particle distributions for a Pittsburgh No. 8 seam coal. 


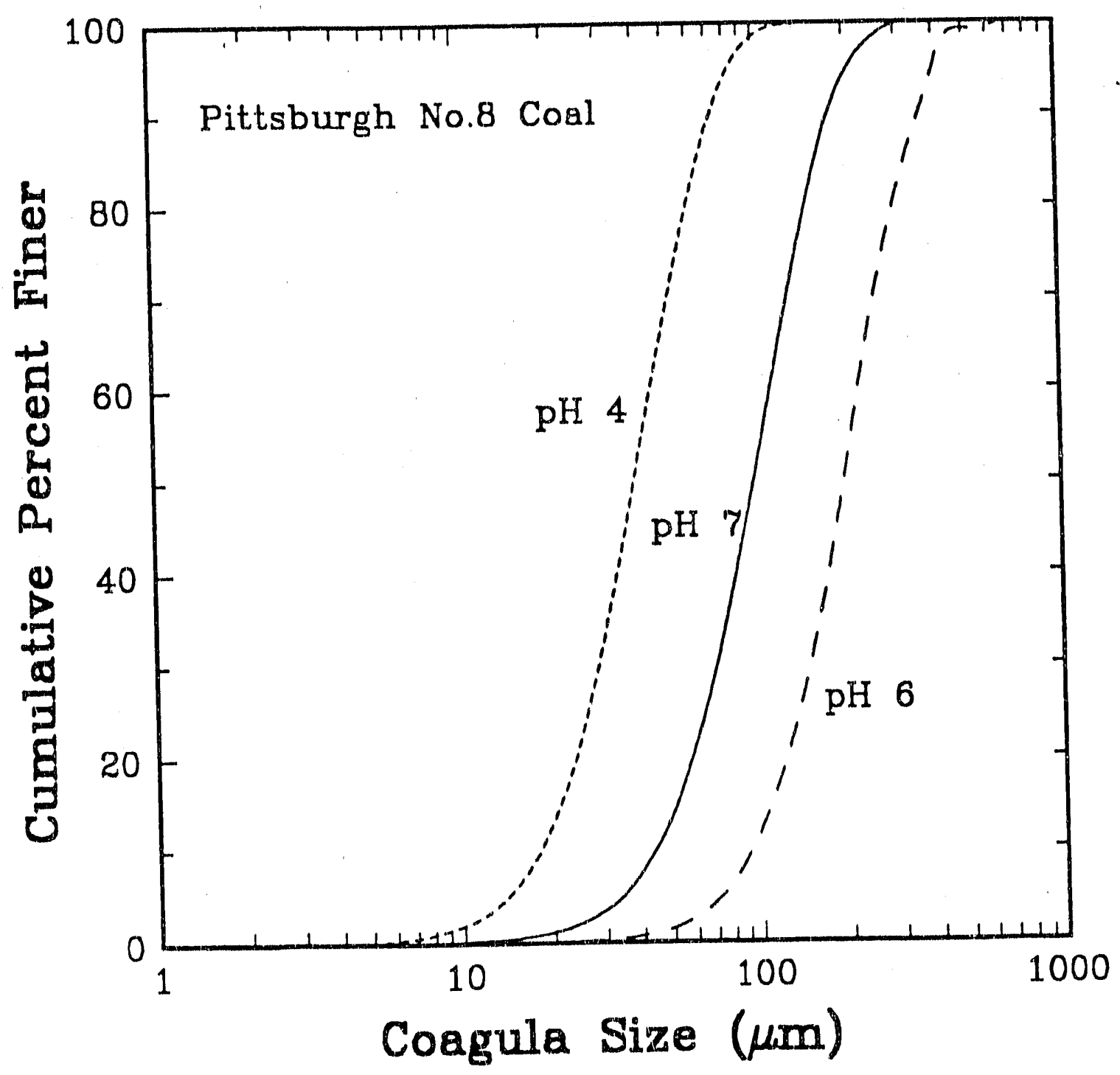

Figure 8: The effect of $\mathrm{pH}$ on the coagulation behavier of a Pittsburgh No. 8 seam coal. 
also investigated. The coagula size distributions were measured for agitation speeds of $25,50,100$, and $300 \mathrm{rpm}$ at a constant $\mathrm{pH}$ of 6.5 . The results of these tests, plotted in Figure 9, indicate that an increase in agitation speed causes a corresponding decrease in the coagula size distribution. The maximum mean coagula diameter of $143 \mu \mathrm{rn}$ was obtained at an agitation speed of $25 \mathrm{rpm}$, while a speed of $100 \mathrm{rpm}$ resulted in a coagula $D_{s 0}$ of less than $18 \mu \mathrm{m}$. As discussed previously in Task 3.3 of the third technical progress report, an increase in agitation speed creates turbulence that tears the coagula apart. This indicates that the forces that hold the particles together are relatively weak, possibly because of the relatively small contact area between individual coal particles.

The combined effects of $\mathrm{pH}$ and agitation speed on the coagulation behavior of the Pittsburgh No. 8 seam coal are dernonstrated in Figure 10. As shown, the optimum coagula size for the Pittsburgh No. 8 sample was obtained at the lowest agitation speed of $25 \mathrm{rpm}$ and at a pH between 6 and 6.5. It is likely that the coagula size decreased sharply above pH 6.5 due to the increased magnitude of the repulsive electrostatic interaction energy $\left(V_{R}\right)$. Calculations indicate that $V_{R}$ exceeds the attractive surface interaction energies $\left(V_{A}\right.$ and $\left.V_{H}\right)$ above $\mathrm{pH}$ 6.2. Since the iso-electic point (iep) of the Pittsburgh No. 8 coal was found to be approximately 4.0 , the decrease in the coagula size below pH 6 is more difficult to explain. Further study is warranted in order to develop a better understanding of this phenomenon.

\section{Task 3. Process Development}

\section{Task 3.4 Development of Methods for Enhancing the Separation of Coagula}

\section{Task 3.4.3 Addition of a Hydrocarbon Oil}

One of the shortcomings of the selective hydrophobic coagulation process is that the resulting coagula are relatively small. These "micro-coagula" settle relatively slowly and, as a result, are difficult to separate using standard sedimentation techniques. One possible method of improving settling rates is to increase the coagula size by adding small amounts of hydrocarbon oil. When used in small quantities, this oil may increase the size of the coagula by enhancing the hydrophobicity of 


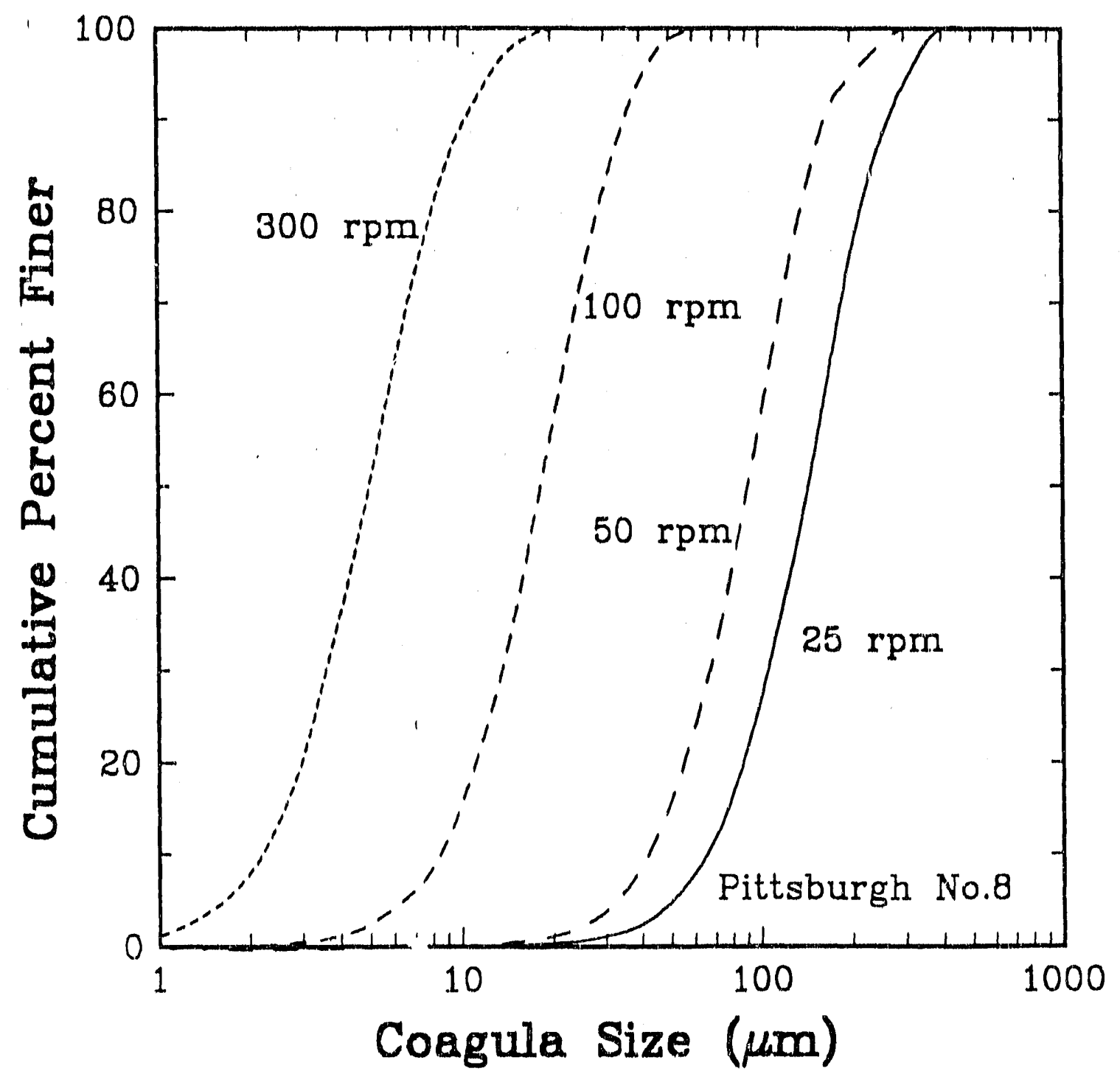

Figure 9: The effect of agitation on the coagulation behavior of a Pittsburgh No. 8 seam coal. 
the coal. During this quarter, tests were conducted to determine how the addition of kerosene, diesel fuel, and a coal oll byproduct from a coal gasification process might affect coagula size. These experiments were carried out at $\mathrm{pH} 8.0$, which is close to the critical $\mathrm{pH}$ for the coagulation of Elkhorn No. 3 coal. The hydrocarbons were added as emulsions containing $0.08 \%$ oil by mass in distilled water. Each coal sample was ground in an attrition mill for 30 minutes to produce a $3.5 \mu \mathrm{m}$ mean size, and then transferred to the mixing vessel. Distilled water was used to adjust the slurry solids content to $1.5 \%$, and the $\mathrm{pH}$ was adjusted to the desired level with either $\mathrm{NaOH}$ and $\mathrm{HCl}$. After the $\mathrm{pH}$ stabilized, the desired amount of oil emulsion was injected by a syringe into the agitated slurry.

The results of the hydrocarbon addition experiments are summarized in Figures 11-13. In each series of tests, coagula size was determined as a function of agitation intensity for various dosages of each hydrocarbon emulsion. In each figure, the mean coagula diameter measured using the Lasentec analyzer was plotted versus the calculated kinetic energy of mixing $\left(V_{k}\right)$. Unfortunately, the test data shown in Figures 11-13 indicate that there was considerable scatter in the measured coagula size distributions. In order to eliminate the possibility that the scatter in the data might be a result of conducting the tests near the critical pH, a second series of tests was carried out at $\mathrm{pH} 7.45$. Only two oils, kerosene and diesel were used in the second series of tests. As shown in Figures 14 and 15 , the test data obtained in this series of tests also display considerable scatter. While a complete explanation for the data scatter is not available, it is possible that hydrocarbon oils may have coated the optical lens of the Lasentec analyzer and interfered with the measurements.

Despite the presence of signiflcant data scatter, several important conclusions can be drawn from the test results shown in Figures 11-15. First, the test results demonstrate that mixing intensity adversely affects coagula size. In all cases studied, the mean coagula size decreased sharply as the kinetic energy of mixing increased. This suggests that the coagula formed by the SHC process are relatively weak and that the turbulence within the separator must be kept to a minimum to prevent 


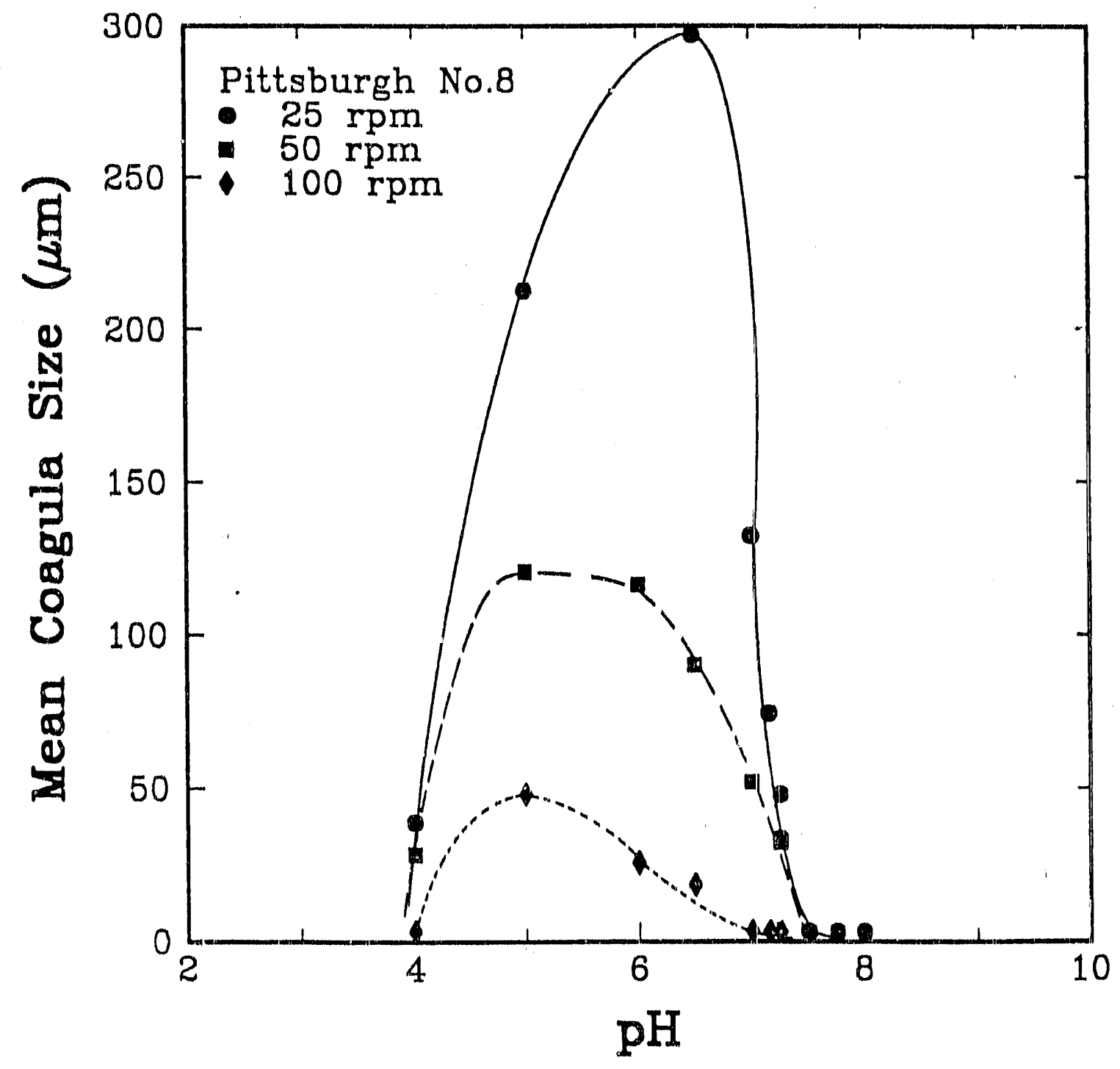

Figure 10: Mean coagula size at different mixing intensities $v s$. pH for a Pittsburgh No. 8 seam coal. 


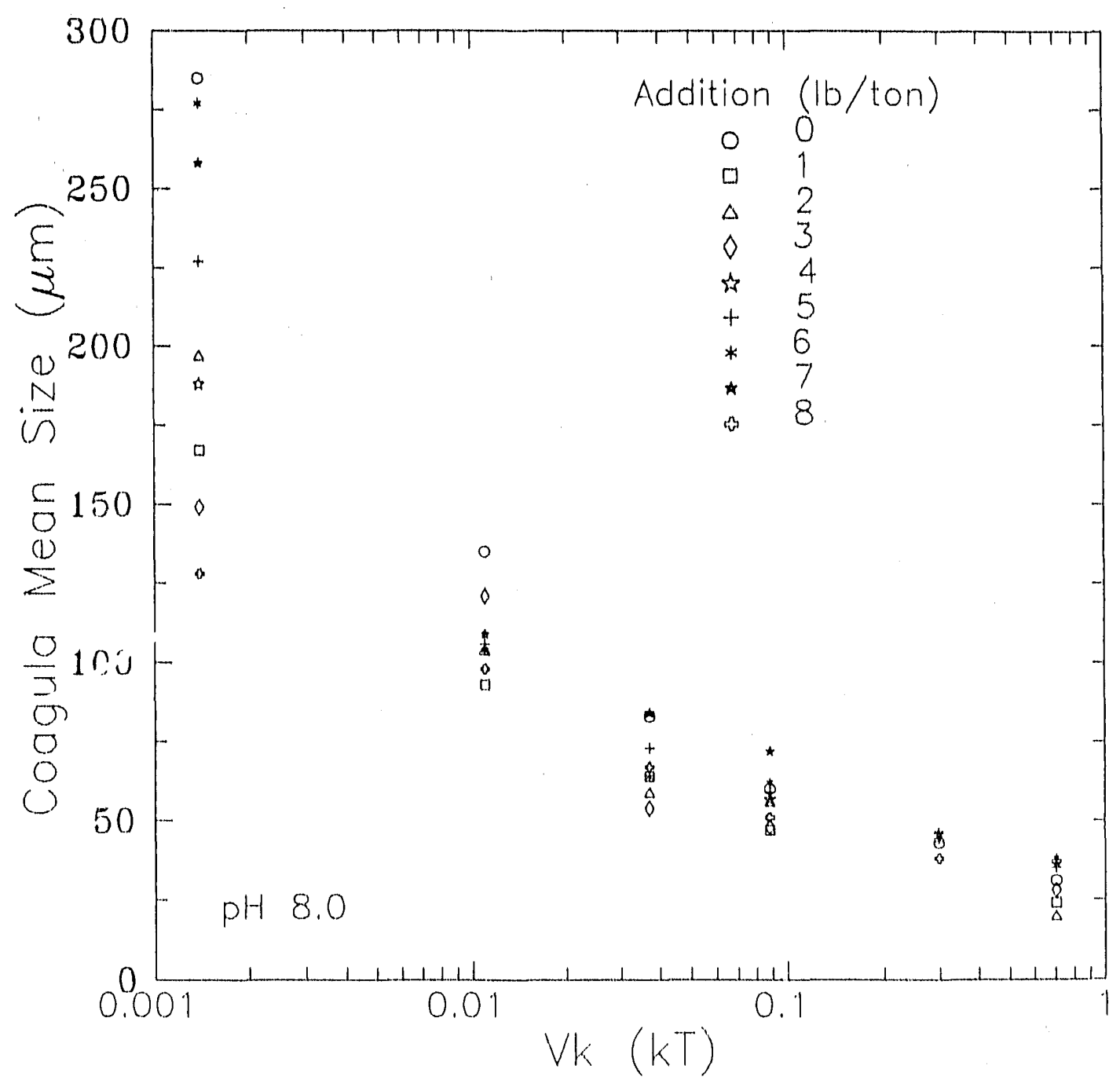

Figure 11: Effect of kerosene addition and mixing intensity on mean coagula size for Elkhorn No. 3 seam coal. 


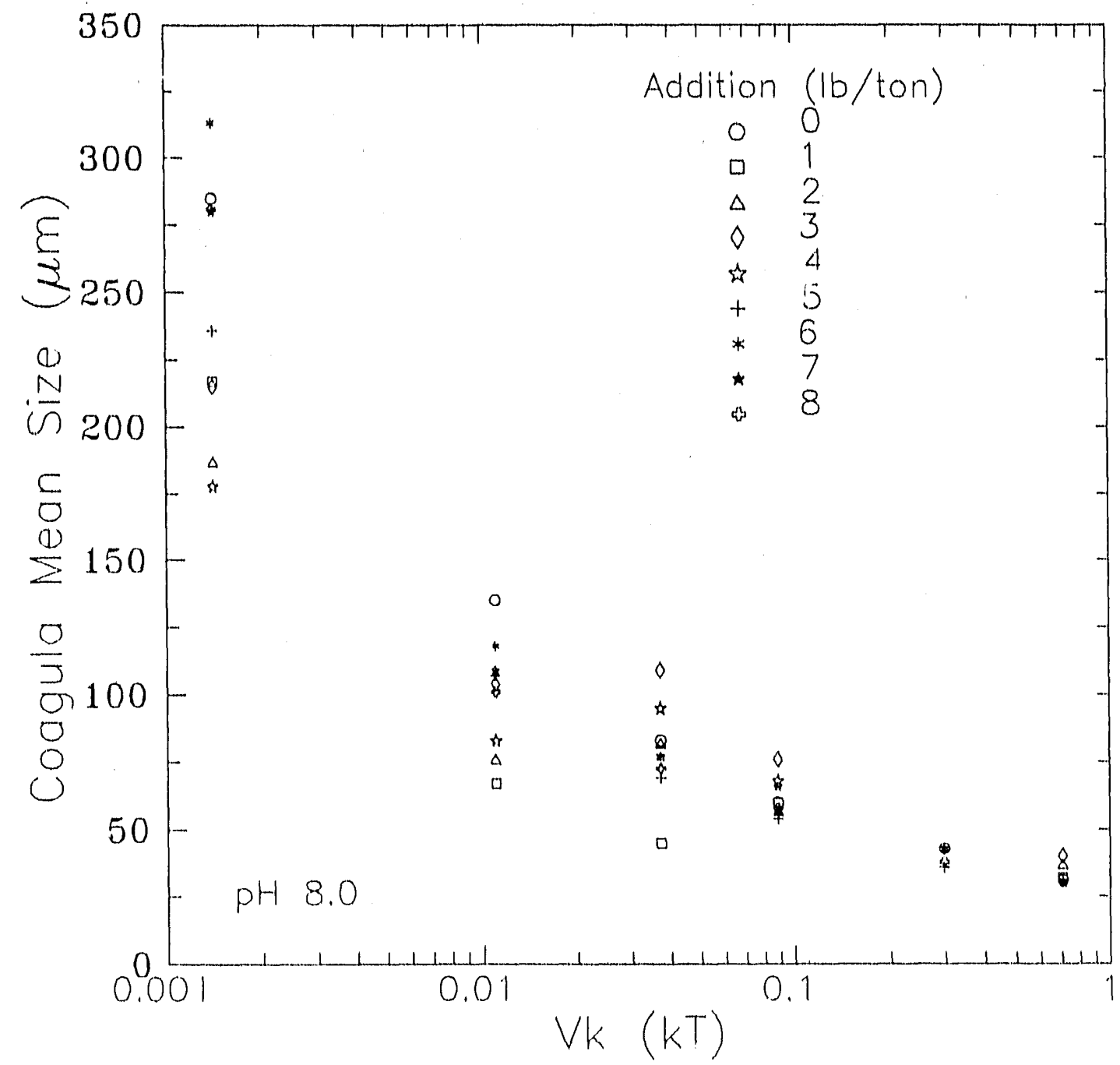

Figure 12: Effect of diesel addition and mixing intensity on mean coagula size for Elkhorn No, 3 seam coal. 


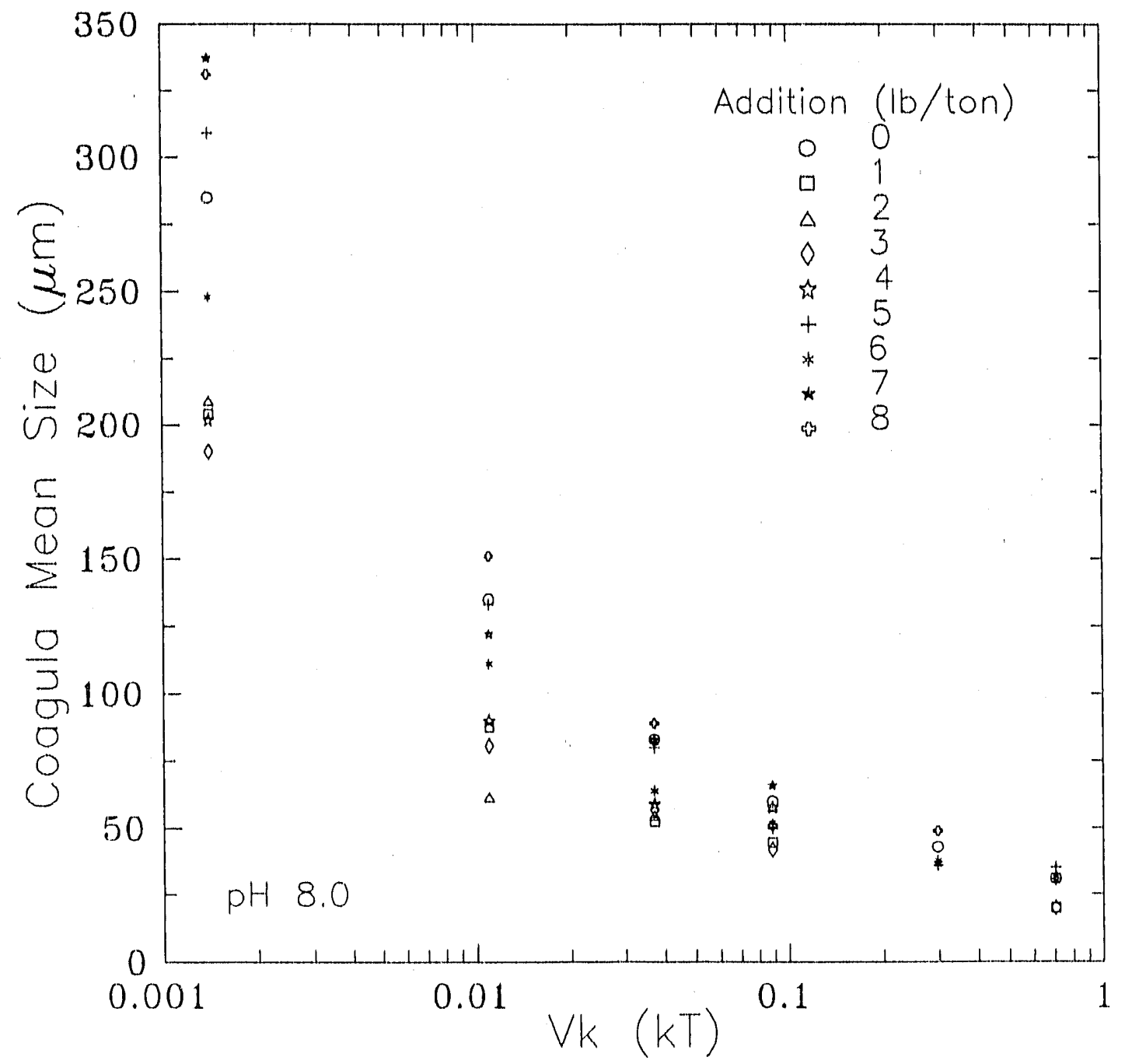

Figure 13: $\quad$ Effect of coal-oil addition and mixing intensity on mean coagula size for Elkhorn No. 3 seam coal. 


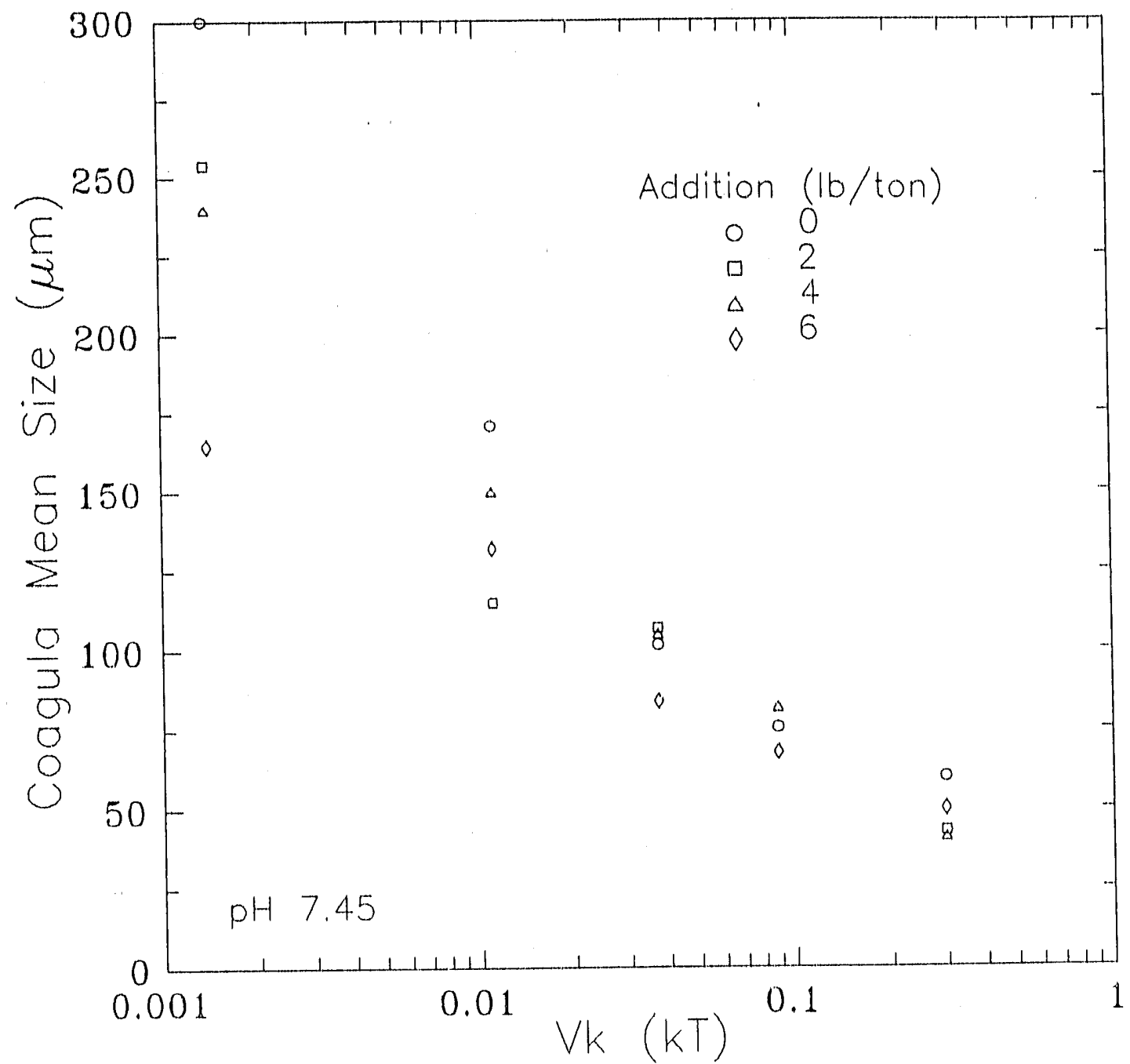

Figure 14: $\quad$ Effect of kerosene additions and mixing intensity on mean ruagula size for Elkhorn No. 3 seam coal at $\mathrm{pH} 7.45$. 


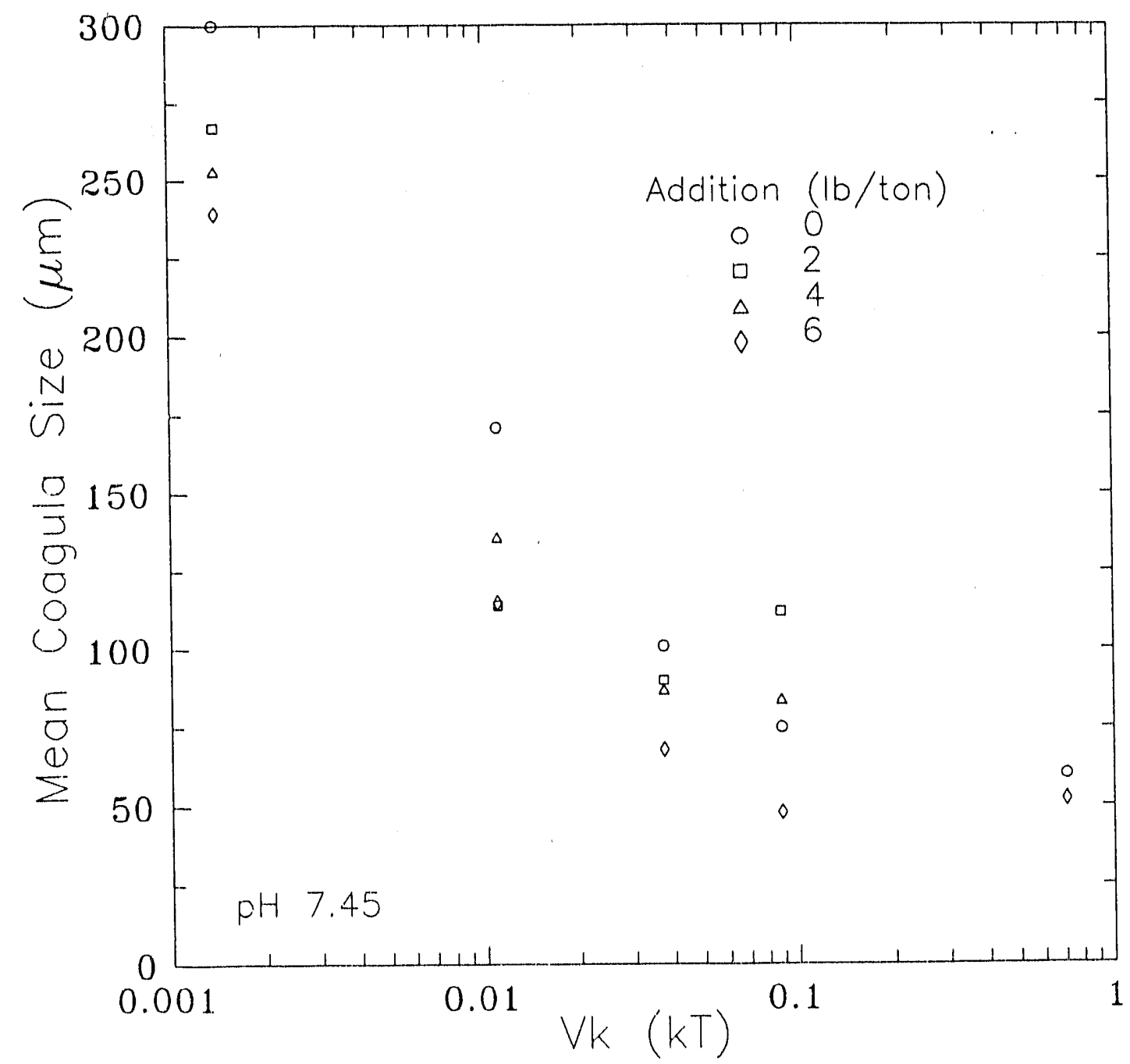

Figure 15: Effect of diesel addition and mixing intensity on mean coagula size for Elkhorn No. 3 seam coal at $\mathrm{pH} 7.45$. 
breakup of the coagula. The test results also indicate that the effects of the hydrocarbon additions on coagula size are less pronounced as the agitation intensity increases. At high agitation intensities (e.g., $>0.1 \mathrm{kT}$, , the measured coagula size becomes relatively constant regardless of the hydrocarbon dosage. At lower agitation intensities, no clearly discernible relationship between hydrocarbon addition and coagula size can be established due to the increased data scatter. However, in nearly every case studied, the largest coagula were obtained in the absence of hydrocarbon additions. This finding suggests that hydrocarbon oils inhibit the growth of coagula, the only notable exception to this conclusion being coal oil at higher addition rates. An explanation for these differences has not yet been established.

\section{Tásk 3.6 Bench-Scale Continuous Testing}

\section{Task 3.6.1 Low-Sulfur Coal Tests}

During this quarter, continuous $S H C$ tests were conducted using a low-sulfur Elkhorn No. 3 seam coal seam $(22.5 \%$ feed ash). Tests were performed using an 11 -inch diameter sedimentation tank separator that was described in Task 3.5 of our second technical progress report. Experiments were conducted to determine the effects of feed rate, solids concentration, $\mathrm{pH}$, initial particle size, and the addition of chemical additives (e.g., chelating agents and dispersants) on separator performance. The primary goal of this exercise was to demonstrate the continuous operation of the bench-scale $S H C$ process at a $1-2 \mathrm{lb} / \mathrm{hr}$ of feed rate.

The continuous SHC tests were conducted using samples that were ground to $2.8 \mu \mathrm{m}$ in a stirred ball mill. Unless otherwise indicated, the solids concentration for each test was maintained at $3 \%$ solids by weight using tap water. The $\mathrm{pH}$ of the coal slurry was adjusted to the desired value (usually 7.5 ) through the addition of sodium hydroxide. The standard operating conditions used throughout the test program were: 


$\begin{array}{lll}\text { Feed Rate } & = & 250 \mathrm{ml} / \mathrm{min} \\ \text { Feed Solids } & = & 3 \% \\ \text { Feed Point } & = & 11 / 4 \mathrm{in} \\ \text { Mudline } & =41 / 2 \mathrm{in} \\ \mathrm{pH} & =7.5\end{array}$

Both the location of the feed point and mudline were measured from the top of the sedimentation tank. In some experiments, a chelating agent (EDTA) was also added to the suspension at a concentration of $0.3 \mathrm{gm} / \mathrm{liter}$ to complex the multi-valent ions which are believed to suppress the selectivity of the process by inducing coagulation of the mineral matter.

In order to determine the amount of time required for the process to reach steady-state, a preliminary shakedown test was conducted in which samples of the product and reject streams were taken as a function of time and analyzed for ash content. As shown in Figure 16, the process required approximately 80 minutes before the product ash content reached a constant value. Based on a cell volume of 10 liters, the time required to reach steady-state was found to be equal to approximately twice the slurry retention time (i.t., cell volume/feed rate). Therefore, the remaining tests were conducted for a minimum of at least twice the retention time before representative samples of the product, tailings, and feed streams were collected. Each sample collected by this procedure was analyzed for solids concentration and ash content. Steady-state operation was confirmed by backcalculating the feed ash content using mass flow rates of the product, tailing, and feed streams and comparing this result with that determined for the head sample. Coal recovery and separation efficiency values were also calculated for each test.

The first operating parameter examined in the continuous $S H C$ tests was volumetric feed flow rate. A range of feed rates from 200 to $400 \mathrm{ml} / \mathrm{min}$, i.e., a mass feed rate of 0.8 to $1.6 \mathrm{lb} / \mathrm{hr}$, was examined in this test series. Unlike the batch tests, only a single stage of cleaning was employed in the continuous test program. As shown in Table II, the maximum separation efficiency of $49.0 \%$ 


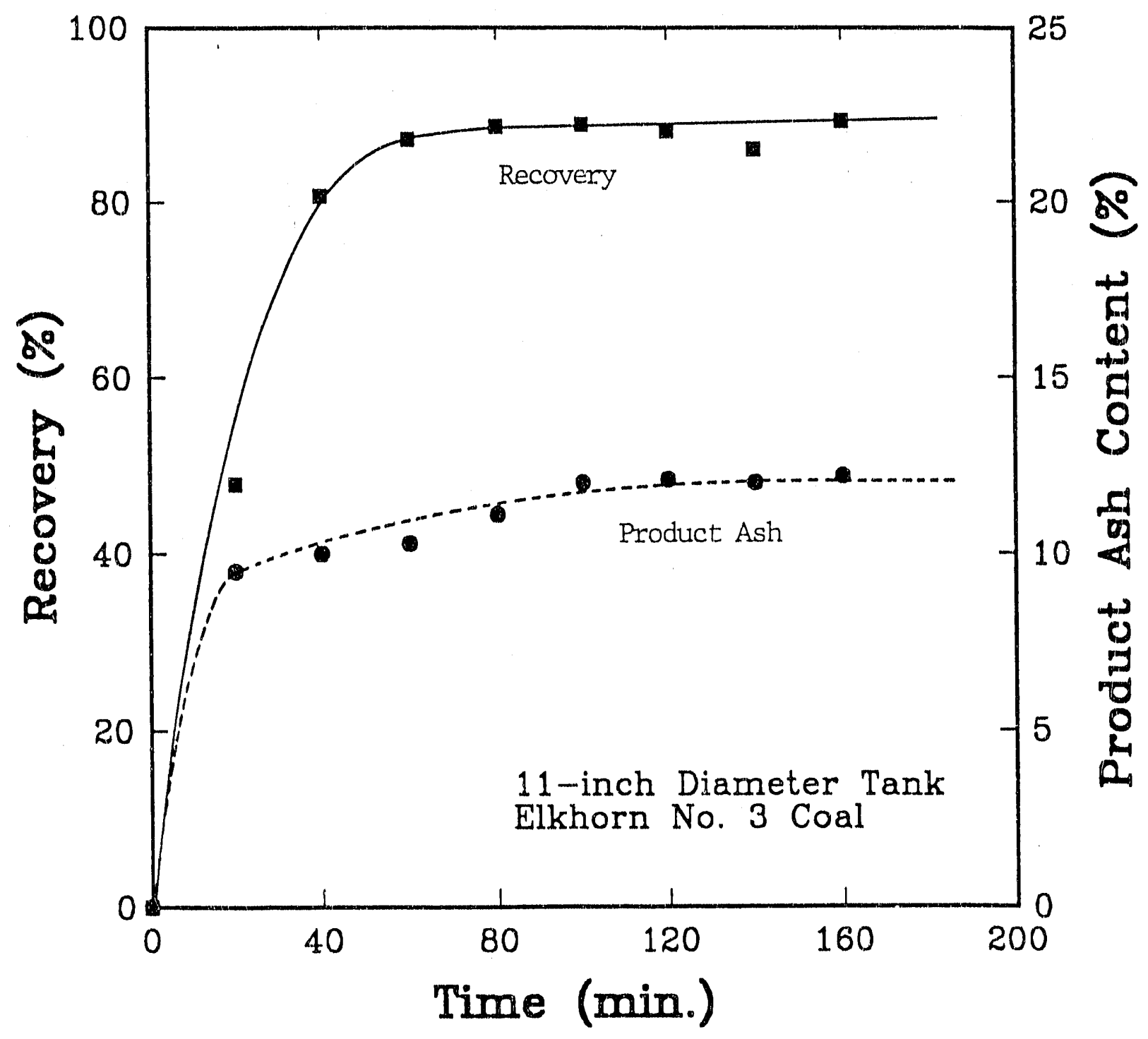

Figure 16: Coal recovery and product ash content $v s$. retention time in the continuous, bench-scale treatment of an Elkhorn No. 3 seam coal. 
(and the minimum product ash value of $10.9 \%)$ was obtained at a feed flow rate of $350 \mathrm{ml} / \mathrm{min}(1.4$ $\mathrm{lb} / \mathrm{hr}$ ). The corresponding combustible recovery obtained at this throughput was $84.7 \%$. A further increase in feed rate caused a substantial drop in combustible recovery due to excessive mixing within the separator. Feed rates lower than $350 \mathrm{ml} / \mathrm{min}$ gave higher combustible recoveries, but also resulted in higher product ash contents. The increase in ash content with decreasing feed rate can be attributed to the accompanying drop in the upward flow velocity in the separator. In order to achieve low ash levels, this velocity must be maintained at a level sufficient to wash the particles of mineral matter out the top of the sedimentation separator.

Table II: Results illustrating the effect of feed rate on the separation performance of the SHC process using an 11-inch diameter sedimentation device.

\begin{tabular}{|c|c|c|c|c|c|}
\hline $\begin{array}{c}\text { Feed Flow } \\
\text { Rate } \\
(\mathrm{ml} / \mathrm{min})\end{array}$ & $\begin{array}{c}\text { Feed Mass } \\
\text { Rate } \\
(\mathrm{lb} / \mathrm{hr})\end{array}$ & $\begin{array}{c}\text { Product } \\
\text { Ash } \\
\text { Content (\%) }\end{array}$ & $\begin{array}{c}\text { Tailing Ash } \\
\text { Content (\%) }\end{array}$ & $\begin{array}{c}\text { Combustible } \\
\text { Recovery } \\
(\%)\end{array}$ & $\begin{array}{c}\text { Separation } \\
\text { Efficiency } \\
(\%)\end{array}$ \\
\hline \hline 200 & 0.8 & 21.4 & 58.3 & 98.3 & 6.34 \\
\hline 250 & 1.0 & 13.3 & 62.4 & 90.9 & 42.9 \\
\hline 300 & 1.2 & 12.1 & 63.2 & 90.3 & 47.5 \\
\hline 350 & 1.4 & 10.9 & 54.9 & 84.7 & 49.0 \\
\hline 400 & 1.6 & 11.2 & 38.1 & 66.4 & 37.5 \\
\hline
\end{tabular}

The effect of variations in the feed solids content was also studied using the continuous $S H C$ separator. Solids concentrations of $2.0 \%$ and $3.0 \%$ by weight were examined over a range of feed rates. As shown in Figure 17, the separation efficiency for both solids concentrations reached a plateau at a volumetric feed flow rate of approximately $250 \mathrm{ml} / \mathrm{min}$. However, the highest overall separation efficiencies were obtained at the lower solids concentration of $2.0 \%$. The decrease in selectivity with increasing particle concentration is probably due to an increase in the entrapment of ultrafine mineral matter in the coal coagula. 


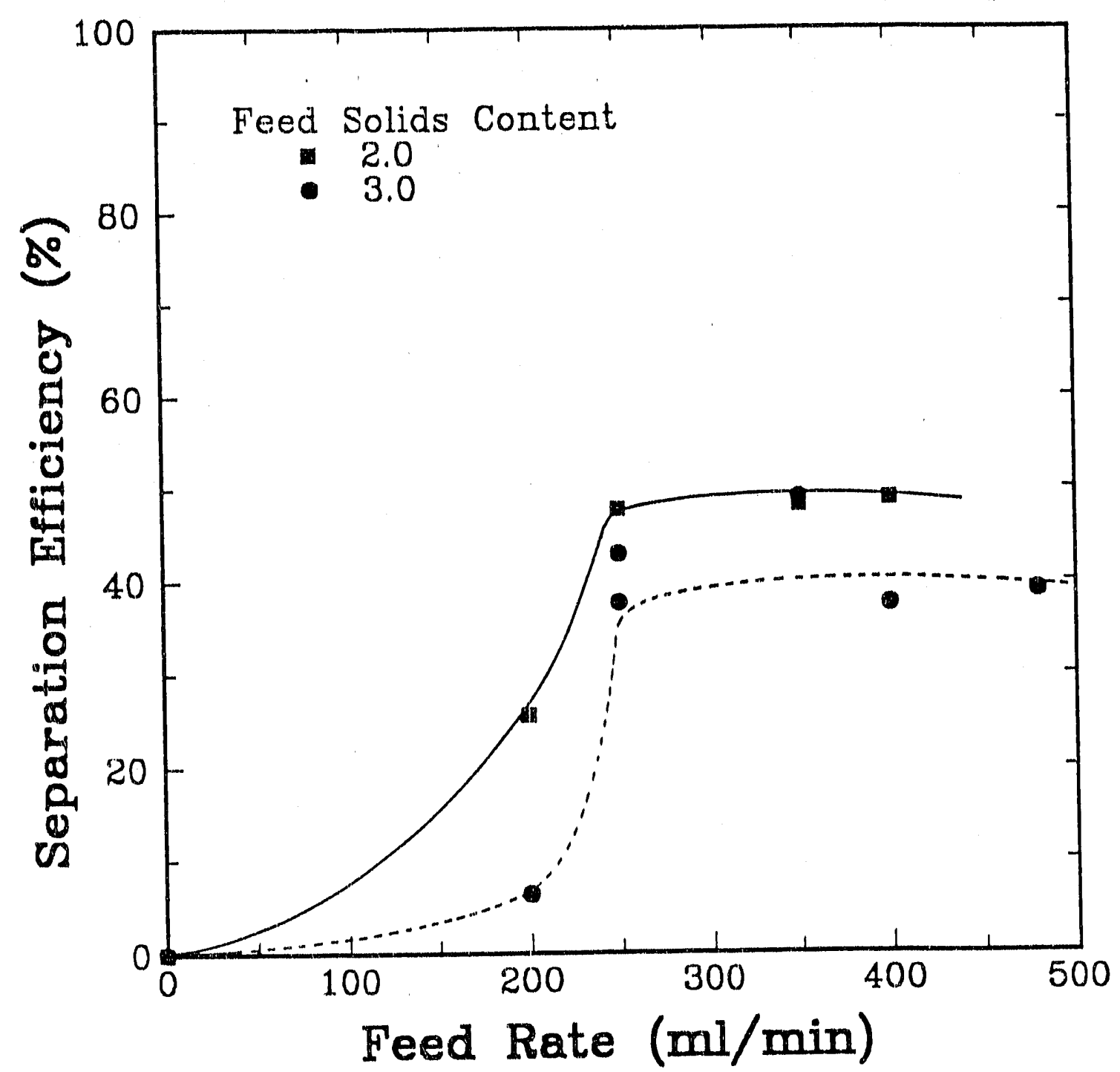

Figure 17: The effect of solids concentration on the separation performance of the continuous SHC unit when processing an Elkhorn No. 3 seam coal. 
Continuous coagulation tests wero also conducted over a pH range from 7.0 to 8.3 in order to determine the effect of $\mathrm{pH}$ on the selectivity of the continuous process. The results of these experiments are given in Table III. As shown, the highest separation efflciency, $42.9 \%$, was obtained at $\mathrm{pH} 7.5$, with corresponding product ash content and recovery values of $13.3 \%$ and $90.9 \%$. The lowest product ash content after a single cleaning stage was obtained at $\mathrm{pH} 8.0$, but the combustible recovery at this $\mathrm{pH}$ was only $67 \%$, resulting in a lower separation efficiency of $38.8 \%$. These results indicate that lower $\mathrm{pH}$ values give higher combustible recoveries, but also higher product ash contents. The increased ash content at the lower $\mathrm{pH}$ values may be due to enhanced heterocoagulation of coal and mineral matter or to the increased entrapment of fine mineral inatter in the larger coal coagula formed at this $\mathrm{pH}$. Low recoveries and high product ash values were obtained at $\mathrm{pH}$ values greater than 8.0 due to the increased dispersion of the coal particles. Thus, the optimum operating $\mathrm{pH}$ for this particular coal lies between 7.5 and 8.0 .

Table III: $\quad$ Results illustrating the effect of $\mathrm{pH}$ on the efficient separation of selectively coagulated Elkhorn No. 3 coal from its associated mineral matter using an 11-inch diameter continuous sedimentation device.

\begin{tabular}{|c|c|c|c|c|}
\hline pH & $\begin{array}{c}\text { Product Ash } \\
\text { Content } \\
(\%)\end{array}$ & $\begin{array}{c}\text { Tailing Ash } \\
\text { Content } \\
(\%)\end{array}$ & $\begin{array}{c}\text { Combustible } \\
\text { Recovery } \\
(\%)\end{array}$ & $\begin{array}{c}\text { Separation } \\
\text { Efriciency } \\
(\%)\end{array}$ \\
\hline \hline 7.0 & 14.9 & 74.6 & 96.0 & 40.0 \\
\hline 7.5 & 13.3 & 62.4 & 90.9 & 42.9 \\
\hline 8.0 & 10.9 & 38.7 & 67.0 & 38.8 \\
\hline 8.3 & 13.8 & 24.4 & 20.2 & 9.10 \\
\hline
\end{tabular}

The effect of initial feed particle size on the coagulation behavior of coal samples obtained from the Elkhorn No. 3 coal seam was also examined during this reporting period. In these tests, samples of the feed coal were ground to mean particle diameters of 7.5, 5.2, 4.1, and $2.8 \mu \mathrm{m}$ using a stirred ball mill. As shown in Table IV, the test data obtained with this coal indicate that a decrease 
in partlcle size results in a higher overall separation efflelency and a lower product ash content. This improvement may be caused by the increased liberation of mineral mattor, a decrease in the settling velocity of the finely pulverized particles of mineral matter, and/or the formation of larger coagula as described previously in Task 2.4. Unfortunately, the effects of initial particle size on combustible recovery are unclear in this serles of test runs.

Table IV: $\quad$ Results illustrating the effect of particle size on the separation performance of the SHC process using an 11-inch diameter sedimentation device.

\begin{tabular}{|c|c|c|c|c|}
\hline $\mathbf{D}_{50}$ & $\begin{array}{c}\text { Product Ash } \\
\text { Content } \\
(\%)\end{array}$ & $\begin{array}{c}\text { Tuiling Ash } \\
\text { Content } \\
(\%)\end{array}$ & $\begin{array}{c}\text { Combustible } \\
\text { Recovery } \\
(\%)\end{array}$ & $\begin{array}{c}\text { Separation } \\
\text { Efficiency } \\
(\%)\end{array}$ \\
\hline \hline 2.8 & 7.11 & 50.0 & 76.9 & 56.6 \\
\hline 4.1 & 9.35 & 44.4 & 73.1 & 47.1 \\
\hline 5.2 & 11.3 & 49.9 & 81.2 & 45.7 \\
\hline 7.5 & 13.5 & 41.5 & 75.8 & 35.1 \\
\hline
\end{tabular}

In an attempt to improve the selectivity of the $S H C$ process, the individual and combined effects of the addition of dispersant (sodlum hexametaphosphate) and chelating agent (EDTA) were also investigated. The dispersant was used to increase the electrostatic charge on the surface of the mineral matter, thereby retarding the coagulation of mineral matter. The chelating agent was added in an attempt to complex multi-valent ions that have been shown to adversely impact the selectivity of the process. In order to establish a baseline result, neither EDTA or sodium hexametaphosphate (HMP) was added in the first continuous test run. As shown in Table V, the baseline tests resulted in a very high combustible recovery of $99.5 \%$ and a corresponding product ash value almost equal to that of the feed material. The addition of $4.0 \mathrm{lb} /$ ton of the dispersant reduced the product ash content was reduced from $22.4 \%$ to $14.8 \%$ with very little loss in combustible recovery. By comparison, the addition of the shelating agent alone reduced the product ash content to $13.3 \%$ at a somewhat lower recovery of $90.9 \%$. However, the best results were obtained by adding both a chelating agent and 
dispersant. The comblned reagent package resulted in the lowest product ash value, $12,6 \%$, at a combustible recovory greater than $96 \%$. This test run also gave tho highest overall saparation efflctency.

Tablo V: Results showing the effect that dlspersant and/or chelating agent additions have on the separation performance of the SHC process.

\begin{tabular}{|c|c|c|c|c|c||}
\hline Dispersunt & $\begin{array}{c}\text { Cheluting } \\
\text { Agent } \\
(\mathrm{gm} / \mathrm{b} / \mathrm{t})\end{array}$ & $\begin{array}{c}\text { Product }) \\
\text { Ash } \\
\text { Content } \\
(\%)\end{array}$ & $\begin{array}{c}\text { Tailing Ash } \\
\text { Content } \\
(\%)\end{array}$ & $\begin{array}{c}\text { Combustiblo } \\
\text { Recovery } \\
(\%)\end{array}$ & $\begin{array}{c}\text { Separation } \\
\text { Efficiency } \\
(\%)\end{array}$ \\
\hline \hline 0.0 & 0.0 & 22.4 & 59.7 & 99.5 & 1.44 \\
\hline 4.0 & 0.0 & 14.8 & 81.6 & 97.3 & 39.1 \\
\hline 0.0 & 0.4 & 13.3 & 62.4 & 90.9 & 42.9 \\
\hline 4.0 & 0.4 & 12.6 & 79.9 & 96.2 & 48.6 \\
\hline
\end{tabular}

It should be emphasized that the data shown In Tables II-V wero obtained after only a singlo stage of treatment by the SHC process. As a result, the ash and sulfur contents of the clean coal products were significantly higher than would be obtained after several stages of recleaning. Tho low rejection per stage in the $S H C$ process can be attributed to the large amount of mineral matter entrained and/or entrapped within the settled coal coagula. The agglomerants formed by traditional oll-based agglomeration processes are considerably stronger and can withstand screening and washing steps designed to remove the entrained/entrapped particles of mineral matter. The washing step allows high grade products to be achieved in a single stage of processing. Unfortunately, as discussed in Task 3.4, the coagula formed by the SHC process are substantlally weaker and cannot be subjected to a fresh water wash without a significant degree of breakup and subsequent loss of the coal coagula. Therefore, several stages of recleaning are required in order to effectively redisperse the entrapped material and to dilute it to a sufficient level that does not adversely impact product quality. The second year of funding for this project will focus on the development of new techniques for enhancing 
the recovery of the hydrophoble coal coagula without the need for multiplo stages of recleaning.

\section{Task 3.6.2 Hlgh-Sulfur Coal Tests}

During tho past roporting porlod, continuous SHC tests wero conducted on the Plttsburgh No. 8 seam coal $(12.2 \%$ ash $)$ to test the feasibility of using this process to treat high sulfur coals. The processing of these coals was of some concern due to the observed natural hydrophobicity off some coal pyrites and the inherently high concontration of iron lons associated with coals having high pyrite contents. The separation was further complicated by the weakly hydrophobic nature of the Pittsburgh No, 8 seam coal, which only coagulates at low pH values.

Samples were prepared for testing by grinding the raw coal for 30 minutes in a laboratory attrition mill containing $1 / 8-$ Inch stainless steel grinding medla. Tho ground slurry was diluted to $3 \%$ solids by welght and then introduced into the continuous sedimentatlon separator. The Initial test work indleated that the Pittsburgh No, 8 seam coal coagulated very poorly above pH 7.0 due to its Low characteristic hydrophoblclty. Therefore, most of the tests with this coal wore carried out in tho neutral pH region. EDTA was added to the slurry at a concentration of $0.4 \mathrm{gm} / \mathrm{liter}$ of suspension to complex the multi-valent lons that are present in the low pH region and adversely affect the selectivity of the process. After the addition of the chelating agent, the $\mathrm{pH}$ was adjusted to the desired value using sodium hydroxide and conditioned for 10 minutes.

Single stage coagulation tests were conducted at $\mathrm{pH}$ values of $6.5,7.0$, and 7.8 . The feed was introduced into the center of the sedimentation tank $11 / 4$ inches from the top at a rate of 250 $\mathrm{ml} / \mathrm{min}$, and the depth of the mudline was maintained at $4 \frac{1}{2}$ inches from the top of the cell by adjusting the rate at which the product was withdrawn from the bottom of the tank. As shown in Table VI, the best selectivity was obtained at $\mathrm{pH} 7,0$. At this $\mathrm{pH}$, the separation efficiency and product ash content were found to be only $17.2 \%$ and $10.1 \%$. A somewhat higher recovery was obtained at $\mathrm{pH} 6.5$, possibly because the coagula are larger at this $\mathrm{pH}$, but the product ash was reduced to only $11.5 \%$. At pH 7.8 , the coal recovery and separation efficiency were both very poor 
because of tho nearly comploto dispersion of the partloles.

Table VI: Results lliustrating tho offoct of pH on the officlent separation of selectively coagulated Plttsburgh No. 8 coal from lts assoclated mineral matter using an 11-Inch diameter continuous sedimentation dovice.

\begin{tabular}{|c|c|c|c|c|}
\hline$p H$ & $\begin{array}{c}\text { Product Ash } \\
\text { Content } \\
(\%)\end{array}$ & $\begin{array}{c}\text { Talling Ash } \\
\text { Content } \\
(\%)\end{array}$ & $\begin{array}{c}\text { Combustible } \\
\text { Recovery } \\
(\%)\end{array}$ & $\begin{array}{c}\text { Soparation } \\
\text { Efficiency } \\
(\%)\end{array}$ \\
\hline 6.5 & 11.5 & 40.9 & 98.8 & 4.84 \\
\hline 7.0 & 10.1 & 27.8 & 90.5 & 17.2 \\
\hline 7.8 & 10.6 & 12.6 & 33.4 & 4.26 \\
\hline
\end{tabular}

\section{Task 3.7 Process Optimization}

During this reporting poriod, a Box-Behnken experimental test design was used to examine the effects of key operating parameters on the performance of an 8-Inch dlameter SHC continuous scparator. The operating parameters examined in this work included volumetric feed flow rate, feed solids content, mudline level and feed injection point. The test matrix required that 27 individual test runs be conducted in order to fully ascertain the effects of these operating parameters. The range examined for each operating parameter and the test run order are summartzed in Table VII. The experiments have been completed and the test data are currently being analyzed using the DESIGNEXPERT software. The results of these analyses will be presented in the final technical progress report.

\section{SUMMARY, STATUS AND PLANNED WORK}

Additional test work still remains to be completed in Task 2.1 (Surface Forces Measurement) where the interaction forces between mica surfaces coated with DDOA are presently being evaluated. In Task 3.2 (Sample Characterization) the high-G contrifuge has finally been dollvered and is being set up. The proposed centrifugal float-sink studles with the Elkhorn No, 3 and Pittsburgh No. 8 coal samples should be completed shortly. Additional tests will also be conducted in Task 3.6.2 (High- 
Tablo VII: The Box-Bohnken test deslgn for the continuous SHC process utillzing a sedimentation tank for separating the selectively coagulated coal from its associated mineral matter.

\begin{tabular}{|c|c|c|c|c|}
\hline $\begin{array}{c}\text { Run } \\
\text { Order }\end{array}$ & $\begin{array}{c}\text { Feed Rute } \\
\text { (ml//nin) }\end{array}$ & $\begin{array}{c}\text { Solids } \\
\text { Content }(\%) \\
\end{array}$ & $\begin{array}{l}\text { Mudline } \\
\text { (crn) }\end{array}$ & $\begin{array}{l}\text { Feed Point } \\
\text { (cm) }\end{array}$ \\
\hline 1 & 50.0 & 3.0 & 10.0 & 6.985 \\
\hline 2 & 50.0 & 2.0 & 11.5 & 6.985 \\
\hline 3 & 50.0 & 4.0 & 11.5 & 5.080 \\
\hline 4 & 50.0 & 2.0 & 13.0 & 5.080 \\
\hline 5 & 35.0 & 3.0 & 10.0 & 5.080 \\
\hline 6 & 50.0 & 3.0 & 11.5 & 5.080 \\
\hline 7 & 50.0 & 2.0 & 11.5 & 3.175 \\
\hline 8 & 65.0 & 3.0 & 11.5 & 3.175 \\
\hline 9 & 35.0 & 2.0 & 11.5 & 5.080 \\
\hline 10 & 35.0 & 3.0 & 11.5 & 6.985 \\
\hline 11 & 65.0 & 3.0 & 13.0 & 5.080 \\
\hline 12 & 50.0 & 4.0 & 11.5 & 3.175 \\
\hline 13 & 50.0 & 3.0 & 13.0 & 6.985 \\
\hline 14 & 50.0 & 4.0 & 13.0 & 5.080 \\
\hline 15 & 50.0 & 4.0 & 11.5 & 6.985 \\
\hline 16 & 50.0 & 3.0 & 11.5 & 5.080 \\
\hline 17 & 65.0 & 3.0 & 10.0 & 5.080 \\
\hline 18 & 50.0 & 3.0 & 13.0 & 3.175 \\
\hline 19 & 65.0 & 2.0 & 11.5 & 5.080 \\
\hline 20 & 50.0 & 2.0 & 10.0 & 5.080 \\
\hline 21 & 65.0 & 3.0 & 11.5 & 6.985 \\
\hline 22 & 35.0 & 3.0 & 13.0 & 5.080 \\
\hline 23 & 50.0 & 3.0 & 11.5 & 5.080 \\
\hline 24 & 35.0 & 3.0 & 11.5 & 3.175 \\
\hline 25 & 50.0 & 4.0 & 10.0 & 5.080 \\
\hline 26 & 65.0 & 4.0 & 11.5 & 6.985 \\
\hline 27 & 50.0 & 3.0 & 10.0 & 3.175 \\
\hline
\end{tabular}



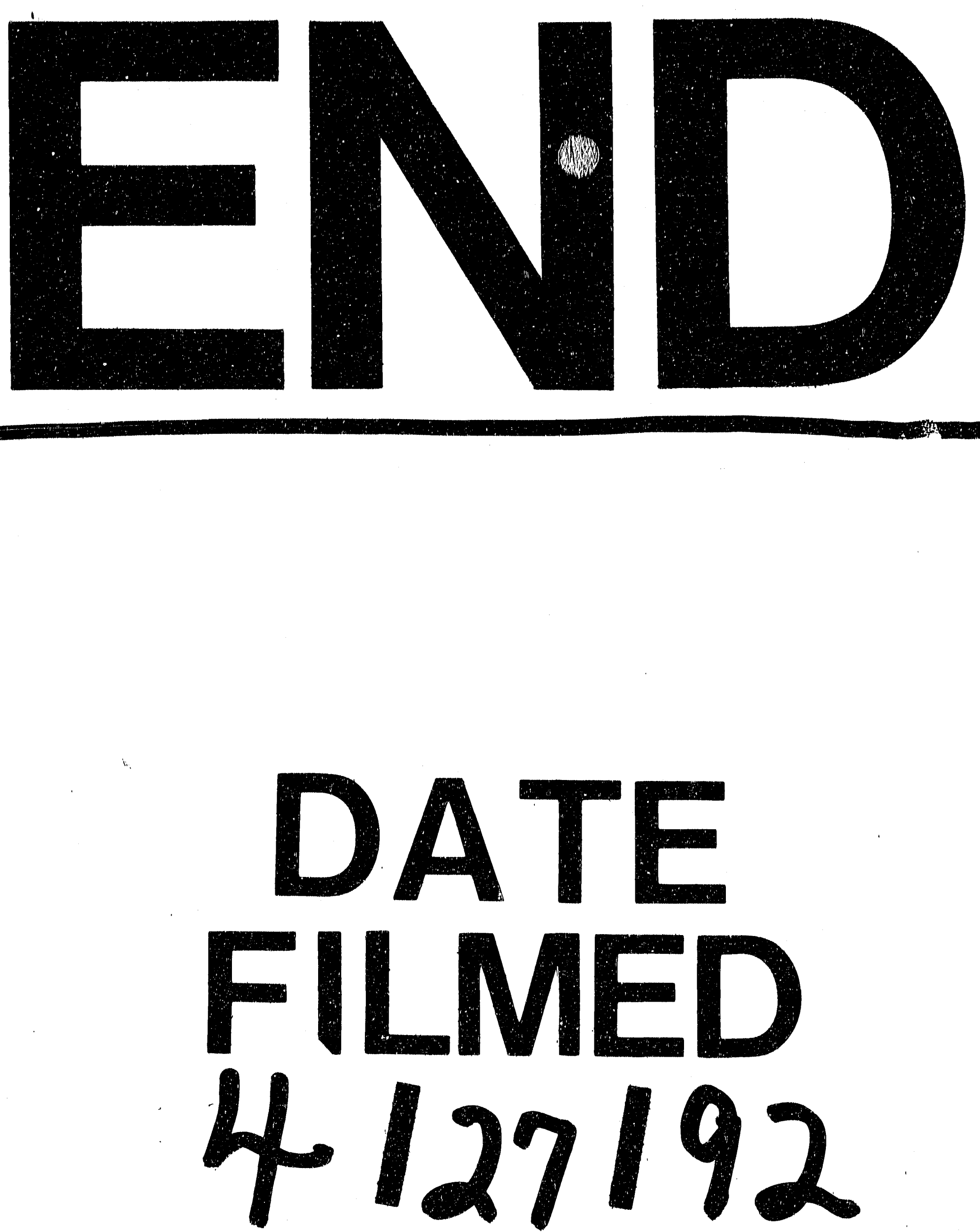
